\title{
Electrical and Network Neuronal Properties Are Preferentially Disrupted in Dorsal, But Not Ventral, Medial Entorhinal Cortex in a Mouse Model of Tauopathy
}

\author{
[Clair A. Booth, ${ }^{1 *}$ (T) Thomas Ridler, ${ }^{2 *}$ Tracey K. Murray, ${ }^{3}$ Mark A. Ward, ${ }^{3}$ Emily de Groot, ${ }^{2}$ Marc Goodfellow, ${ }^{4}$ \\ CKeith G. Phillips, ${ }^{3}$ Andrew D. Randall, ${ }^{1,2}$ and ${ }^{\circ}$ Jonathan T. Brown ${ }^{1,2}$ \\ ${ }^{1}$ School of Physiology and Pharmacology, University of Bristol, Bristol BS8 1TD, United Kingdom, ${ }^{2}$ Institute of Biomedical and Clinical Sciences, University \\ of Exeter Medical School, Hatherly Laboratories, Exeter EX4 4PS, United Kingdom, ${ }^{3}$ Lilly UK, Windlesham, Surrey GU20 6PH, United Kingdom, and \\ ${ }^{4}$ College of Engineering, Mathematics and Physical Sciences, University of Exeter, Exeter EX4 4SB, United Kingdom
}

The entorhinal cortex (EC) is one of the first areas to be disrupted in neurodegenerative diseases such as Alzheimer's disease and frontotemporal dementia. The responsiveness of individual neurons to electrical and environmental stimuli varies along the dorsalventral axis of the medial $\mathrm{EC}(\mathrm{mEC})$ in a manner that suggests this topographical organization plays a key role in neural encoding of geometric space. We examined the cellular properties of layer II mEC stellate neurons (mEC-SCs) in rTg4510 mice, a rodent model of neurodegeneration. Dorsoventral gradients in certain intrinsic membrane properties, such as membrane capacitance and afterhyperpolarizations, were flattened in rTg4510 mEC-SCs, while other cellular gradients [e.g., input resistance $\left(R_{i}\right)$, action potential properties] remained intact. Specifically, the intrinsic properties of rTg4510 mEC-SCs in dorsal aspects of the mEC were preferentially affected, such that action potential firing patterns in dorsal mEC-SCs were altered, while those in ventral $\mathrm{mEC}$-SCs were unaffected. We also found that neuronal oscillations in the gamma frequency band $(30-80 \mathrm{~Hz})$ were preferentially disrupted in the dorsal $\mathrm{mEC}$ of $\mathrm{rTg} 4510$ slices, while those in ventral regions were comparatively preserved. These alterations corresponded to a flattened dorsoventral gradient in thetagamma cross-frequency coupling of local field potentials recorded from the mEC of freely moving rTg4510 mice. These differences were not paralleled by changes to the dorsoventral gradient in parvalbumin staining or neurodegeneration. We propose that the selective disruption to dorsal $\mathrm{mECs}$, and the resultant flattening of certain dorsoventral gradients, may contribute to disturbances in spatial information processing observed in this model of dementia.

Key words: dementia; gamma oscillations; grid cells; medial entorhinal cortex; Tau

\section{Significance Statement}

The medial entorhinal cortex ( $\mathrm{mEC}$ ) plays a key role in spatial memory and is one of the first areas to express the pathological features of dementia. Neurons of the $\mathrm{mEC}$ are anatomically arranged to express functional dorsoventral gradients in a variety of neuronal properties, including grid cell firing field spacing, which is thought to encode geometric scale. We have investigated the effects of tau pathology on functional dorsoventral gradients in the $\mathrm{mEC}$. Using electrophysiological approaches, we have shown that, in a transgenic mouse model of dementia, the functional properties of the dorsal $\mathrm{mEC}$ are preferentially disrupted, resulting in a flattening of some dorsoventral gradients. Our data suggest that neural signals arising in the $\mathrm{mEC}$ will have a reduced spatial content in dementia.

\section{Introduction}

The entorhinal cortex (EC) occupies a pivotal position in the corticohippocampal circuit (Amaral and Witter, 1989; Canto et al., 2008), and is critical for numerous memory functions

Received July 14, 2014; revised 0ct. 29, 2015; accepted Nov. 10, 2015.

Author contributions: M.G., A.D.R., and J.T.B. designed research; C.A.B., T.R., T.K.M., M.A.W., and E.d.G. performed research; K.G.P. contributed unpublished reagents/analytic tools; C.A.B., T.R., T.K.M., M.A.W., and J.T.B. analyzed data; J.T.B. wrote the paper.
(McNaughton et al., 2006). The discovery of grid cells in the medial EC (mEC; Fyhn et al., 2004) highlighted an important role for this region in spatial information processing. Grid cells are

C.A.B. was funded by an MRC-CASE studentship co-funded by Pfizer. T.R. was funded by a University of Exeter and Eli Lilly studentship. T.K.M., M.A.W., and K.G.P. were employees of Eli Lilly. A.D.R. was funded by a Royal Society Industrial Fellowship. J.T.B. was an Alzheimer's Research UK Senior Research Fellow. M.G. and J.T.B. were additionally supported by "Bridging the gaps" funding via the University of Exeter. Eli Lilly provided the rTg4510 mice. We thank H. Hardy and P. Leete for assistance with microscopy.

${ }^{*}$ C.A.B. and T.R. contributed equally to this work. 
anatomically arranged such that the size and spacing of grid cell firing fields increases along the dorsal-ventral axis of the mEC in rats (Hafting et al., 2005; Stensola et al., 2012) and mice (Fyhn et al., 2008), with corresponding gradients in neuronal network properties (Beed et al., 2013), synaptic integration, intrinsic neuronal properties, and morphology of layer II $\mathrm{mEC}$ stellate cells (mEC-SCs; Giocomo et al., 2007; Garden et al., 2008; Giocomo and Hasselmo, 2008, 2009; Boehlen et al., 2010; Navratilova et al., 2012; Yoshida et al., 2013).

The EC is highly vulnerable to degeneration in dementias in which aberrant tau pathology is a cardinal feature, such as Alzheimer's disease and frontotemporal dementia (Braak and Braak, 1991). Despite this, there is a lack of information about the functional consequences of pathological tau deposition in the EC. One commonly used model of tauopathy is the rTg4510 mouse model, which overexpresses a human mutant (P301L) form of the microtubule-associated protein tau, and develops neurofibrillary tangles, age-related forebrain neurodegeneration, and parallel cognitive deficits (Ramsden et al., 2005; Santacruz et al., 2005). Studies of layer III cortical pyramidal neurons have shown that cells from rTg4510 mice exhibit a significantly depolarized resting membrane potential (RMP) compared with wild-type (WT) neurons, as well as increased "sag" upon hyperpolarization, increased excitability, and alterations in spontaneous synaptic currents (Rocher et al., 2010; Crimins et al., 2011, 2012). These studies also revealed morphological alterations, such as decreased dendritic length and complexity, and decreased spine density in rTg4510 neurons, which were preceded by electrophysiological changes. Within the hippocampal formation, an age-dependent decrease in Schaffer collateral LTP (Hoover et al., 2010) and alterations in place cell activity have been documented (Cheng and Ji, 2013). There are, however, no reports examining the neurophysiology of EC neurons in rTg4510 mice. Here, we have characterized the intrinsic electrical properties of layer II mEC-SCs and mEC neuronal network oscillations in rTg4510 mice (Santacruz et al., 2005) to examine the hypothesis that well reported deficits in spatial memory observed in this model of tauopathy (Ramsden et al., 2005) could be, in part, due to alterations in the properties of these neurons.

\section{Materials and Methods}

Procedures were performed in accordance with the Animals (Scientific Procedures) Act 1986. Male rTg4510 and age-matched littermate WT mice (Santacruz et al., 2005) were bred at Charles River or Harlan Laboratories, shipped to the Universities of Bristol or Exeter, or Eli Lilly and housed on a $12 \mathrm{~h}$ light/dark cycle with ad libitum access to food and water. For all experiments, mice were used at 7-8 months of age.

Brain slice electrophysiology. Slices and extracellular solutions were prepared as described previously (Brown et al., 2011) except that parasagittal (300 and $400 \mu \mathrm{m}$, respectively, for whole-cell and extracellular experiments) slices of the $\mathrm{mEC}$ were used. Furthermore, for gamma oscillation recordings, the $\left[\mathrm{Ca}^{2+}\right]_{\mathrm{O}}$ was $1.2 \mathrm{~mm}$. For whole-cell recordings, slices were transferred to a submerged-style recording chamber, perfused with warmed $\left(33 \pm 1^{\circ} \mathrm{C}\right)$, oxygenated $\left(95 \% \mathrm{O}_{2}, 5 \% \mathrm{CO}_{2}\right)$ artificial CSF (aCSF). Neurons in mEC layer II were identified under infrared-differential interference contrast optics.

The authors declare no competing financial interests.

This article is freely available online through the J Neurosci Author Open Choice option.

Correspondence should be addressed to Jonathan T. Brown, Institute of Biomedical and Clinical Sciences, University of Exeter Medical School, Hatherly Laboratories, Prince of Wales Road, Exeter EX4 4PS, UK. E-mail: J.T.Brown@exeter.ac.uk.

DOI:10.1523/JNEUROSCI.2845-14.2016

Copyright $\odot 2016$ Booth, Ridler et al.

This is an Open Access article distributed under the terms of the Creative Commons Attribution License Creative Commons Attribution 4.0 International, which permits unrestricted use, distribution and reproduction in any medium provided that the original work is properly attributed.
Current-clamp recordings were made with glass micropipettes (3-5 $\mathrm{M} \Omega$ ) filled with an internal solution comprising the following (in $\mathrm{mM}$ ): K-Gluconate 140, $\mathrm{NaCl}$ 10, HEPES 10, EGTA 0.2, Na-GTP 0.3, and Mg ATP 4. This resulted in a liquid junction potential error of $15 \mathrm{mV}$, which was corrected post hoc. For extracellular recordings, slices were transferred to an interface-style recording chamber maintained at $34 \pm 1^{\circ} \mathrm{C}$. Simultaneous recordings were made from dorsal and ventral ends of the $\mathrm{mEC}$ using glass micropipettes filled with aCSF. Neuronal network oscillations were elicited by continuous bath application of kainate $(500 \mathrm{~nm})$ for up to $1 \mathrm{~h}$.

Electrophysiological data were recorded using Multiclamp 700A/700B amplifiers. Whole-cell data were low-pass filtered $(10 \mathrm{kHz})$ and digitized at $100 \mathrm{kHz}$. Extracellular data were bandpass filtered $(0.1-1 \mathrm{kHz})$ and digitized at $5 \mathrm{kHz}$. Data were captured using Clampex 10 software and digitally stored for off-line analysis. For whole-cell recordings, only neurons with a series resistance of $<20 \mathrm{M} \Omega$ and a resting membrane potential lower than $-65 \mathrm{mV}$ were included in subsequent analyses. Data analysis was performed using custom-written routines in Matlab. SPSS was used for appropriate statistical analyses. Spikes were defined as occurring in a cluster if two or more consecutive spikes had interspike intervals of $<250 \mathrm{~ms}$, preceded and followed by a quiescent period of $>300 \mathrm{~ms}$. The probability that a spike occurs in a cluster $\left(p_{\text {Clus }}\right)$ was calculated as the ratio of clustered spikes to the total number of spikes (Nolan et al., 2007). The $p_{\text {Clus }}$ was determined from epochs $(\sim 10 \mathrm{~s})$ of spontaneous action potential (AP) firing, by depolarizing neurons using a constant current injection 1-3 times rheobase, such that regular discharges were observed. Medium afterhyperpolarizations (mAHPs) were measured by delivering $50 \mathrm{~Hz}$ trains (consisting of 5-25 pulses) of brief (2 $\mathrm{ms})$ strong $(2 \mathrm{nA})$ stimuli, such that each stimulus resulted in a single AP. Alternatively, we measured mAHPs following single, spontaneous APs evoked by constant current injection (1-3 times rheobase). The mAHP half-width for single spikes was measured at half-maximal amplitude, measured relative to the threshold of the preceding spike.

Histology and immunohistochemistry. Mice were terminally anesthetized and transcardially perfused with $30 \mathrm{ml}$ of PBS, followed by $30 \mathrm{ml}$ of $10 \%$ buffered formalin. Brains were removed and post-fixed in $10 \%$ buffered formalin, before being sagittally bisected into two hemispheres. These segments were processed using the Tissue TEK VIP processor (GMI Inc) and embedded in paraffin wax. From the middle segment, $6 \mu \mathrm{m}$ serial sections (from lateral 2.80 to 3.40, chosen level for immunohistochemistry 3.00) were cut using rotary microtomes (HM 200 and HM 355; Thermo Scientific) and mounted on glass slides.

Following deparaffinization and rehydration, antigen retrieval was performed using the Lab Vision PT Module System (Thermo Scientific), where sections were heated to $100^{\circ} \mathrm{C}$ for $20 \mathrm{~min}$ in citrate buffer (TA-250PM1X; Thermo Scientific). After cooling and washing with warm citrate buffer, the slides were transferred to the Lab Vision Autostainer 360 (Thermo Scientific), where the following incubations were performed: $10 \mathrm{~min}$ in $\mathrm{H}_{2} \mathrm{O}_{2}(0.03 \%)$; 30 min in normal goat serum (1:20; Vector Laboratories); primary antibodies either (1) phosphorylated tau protein [PG5 (pSer409, a gift from Peter Davies, Albert Einstein College of Medicine, New York, NY; 1:8000, room temperature] for $60 \mathrm{~min}$; or (2) PV $\left(1: 5000,4^{\circ} \mathrm{C}\right.$; Swant $)$ for $18 \mathrm{~h}, 30 \mathrm{~min}$ in biotinylated goat anti-mouse IgG (PK-6101; Vector Laboratories), 30 min avidin-biotin complex solution (PK-6101; Vector Laboratories), and $5 \mathrm{~min}$ in 3,3'-diaminobenzidine (SK-4100; Vector Laboratories). Apart from the latter, PBS with $0.05 \%$ Tween-20 (PBS-T) was used for dilution and washes. Following immunohistochemistry, some sections were counterstained with hematoxylin before coverslipping.

Stained sections were digitized using the Scanscope XT slide scanner (Aperio) at $20 \times$ magnification. Imagescope Software (version 11.1.2.760; Aperio) was used to view, delineate, and analyze digitized tissue sections. To analyze tau pathology, PG-5 immunoreactivity was quantified using the positive-pixel algorithm (Imagescope, version 11.1.2.760; Aperio) and was expressed as the percentage of area burden within a delineated region of interest. A similar approach was used to quantify parvalbumin (PV) immunoreactivity in the same delineated region of interest expressed as the percentage of PV intensity.

To assess the gross anatomy of the $\mathrm{mEC}$, additional $6 \mu \mathrm{m}$ sections were stained with cresyl violet solution (Thermo Scientific). After deparaf- 
finization and rehydration, slides were treated with $1 \%$ cresyl violet for 8 min, followed by differentiation in ethanol and acetic acid, and dehydration with increasing concentrations of ethanol. Sections were then treated with xylene and immediately coverslipped with DPX (SigmaAldrich). Images were obtained using a light microscope, and quantification of cortical thickness and cell density was performed with ImageJ software (Schindelin et al., 2012) using the measure and analyze particles tools, respectively. Location of the $\mathrm{mEC}$ was determined with reference to the Allen Developing Mouse Brain Atlas (http://developingmouse.brain-map.org).

In vivo electrophysiology. Mice were chronically implanted with 16channel linear silicon probes (interelectrode spacing, $150 \mu \mathrm{m}$; site impedance, $200-400 \mathrm{k} \Omega$; NeuroNexus Technologies). Animals were anesthetized using isoflurane (4\%) and were fixed into a stereotaxic frame. Anesthesia was then reduced and maintained at $1-2 \%$ during surgery. Probes were implanted at $0.2-0.3 \mathrm{~mm}$ posterior to the transverse sinus, $3.1-3.25 \mathrm{~mm}$ from midline, and $3 \mathrm{~mm}$ below the dura mater. Implants were angled at $10^{\circ}$ in the posterior direction in the sagittal plane to record consistently from layer II/III along the dorsal-ventral axis of the mEC. Gentamycin-impregnated bone cement was used to anchor the probe to the skull, and a silver wire (World Precision Instruments) connected to a watchmakers screw overlying the cerebellum was used as a ground.

After at least 1 week of postoperative recovery, mice were placed on a novel linear track (1.5 m long) and allowed to explore for 15-20 min. Local field potential (LFP) signals were recorded using a Digital lynx $10 \mathrm{~S}$ recording system (Neuralynx) using an HS-18 unity gain headstage and Cheetah 5 data acquisition software (Neuralynx). LFPs were bandpass filtered $(1-500 \mathrm{~Hz})$ and continuously sampled at $2 \mathrm{kHz}$. Two lightemitting diodes on the headstage and an overhead video camera (sample rate, $25 \mathrm{~Hz}$ ) were used to continuously track the location of the animals, allowing the estimation of position and running speed.

At the end of the experiment, mice received an overdose of sodium pentobarbital (Euthetal), and electrolytic lesions were made at four electrode locations. Mice were then transcardially perfused with $4 \% \mathrm{v} / \mathrm{v}$ formaldehyde in $0.1 \mathrm{~m}$ PBS. Brains were extracted from the skull and stored in $4 \%$ formaldehyde before being cut into sagittal sections (50 $\mu \mathrm{m}$ ) using a vibratome (VT1000; Leica) and stained with cresyl violet. The position of electrode sites was determined from digital pictures taken with a $2.5 \times$ objective on a light microscope using QCapture Pro 7 software (Qimaging). Probe electrode location was expressed as the distance from the most dorsal electrode site in layer II/III of the mEC.

All data analysis was performed in Matlab (MathWorks). Epochs of LFP were selected where the speed of the animal was constant (10-15 $\mathrm{cm} / \mathrm{s})$. Spectral analysis of the resulting epochs of LFP was performed using the Chronux toolbox (http://chronux.org/). Modulation index (MI; Canolty et al., 2006) was calculated to measure phase-amplitude coupling between theta and gamma frequency oscillations using a toolbox (http://www.cs.bris.ac.uk/Research/MachineLearning/pac/; Onslow et al., 2011). A linear regression analysis between probe position and MI was performed, and the slope of this line was determined. Furthermore, the Pearson's $R$ value for each correlation was transformed to a normally distributed $z$-score for comparison between the two groups.

\section{Results}

To explore whether the dorsoventral gradients in intrinsic membrane properties of mEC-SCs (Giocomo et al., 2007; Garden et al., 2008; Giocomo and Hasselmo, 2008, 2009; Boehlen et al., 2010; Navratilova et al., 2012; Yoshida et al., 2013) were altered in rTg4510 mice, we made whole-cell recordings from dorsal and ventral layer II mEC neurons (0.5-0.8 and 1.7-2.0 mm, respectively, ventral to the postrhinal cortex border). By recording at either end of the dorsoventral axis, rather than along the entire length (as done by others, Garden et al., 2008), we constructed our hypotheses with a multifactorial design to more readily examine the effects of tauopathy on these gradients. The cell locations were not significantly different between genotypes (mean distance from postrhinal cortex border: WT mice: dorsal, $0.63 \pm$ $0.02 \mathrm{~mm}, n=35$; ventral $1.84 \pm 0.01 \mathrm{~mm}, n=39$; $\mathrm{rTg} 4510$ mice:
Stellate neuron
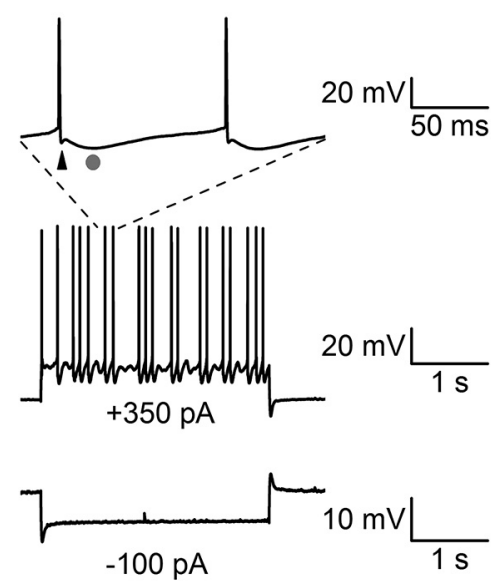

10

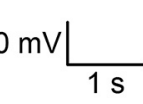

Pyramidal neuron

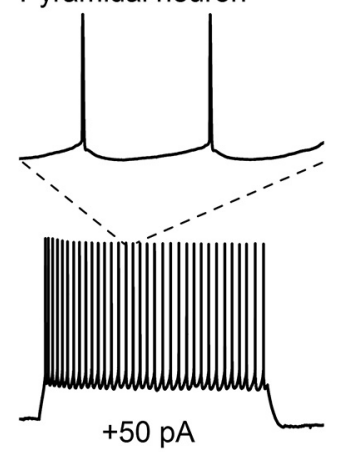

$-100 \mathrm{pA}$
Figure 1. $\mathrm{mEC}$ stellate and pyramidal cells have distinct intrinsic membrane properties Traces are representative whole-cell current-clamp recordings from a stellate (left) or a pyramidal (right) neuron. Bottom traces are voltage responses to a $3 \mathrm{~s},-100 \mathrm{pA}$ square-wave current injection from a fixed potential of $-80 \mathrm{mV}$. Note the substantially higher input resistance of the pyramidal cell and the prominent sag potential in the stellate neuron. The middle traces show the voltage response to a depolarizing current injection of sufficient amplitude to elicit action potential firing. Note the clustered firing pattern of the stellate neuron compared with the relatively tonic firing exhibited by the pyramidal cell. The top traces show two action potentials on an expanded time base. The two components of the biphasic AHP recorded from the stellate cell are marked with an arrowhead (the fast AHP) and a circle (the medium AHP).

dorsal, $0.68 \pm 0.02 \mathrm{~mm}, n=28$; ventral, $1.84 \pm 0.01 \mathrm{~mm}, n=32$; main effect of genotype: $F=0.35, p=0.6$, two-way ANOVA).

In the $\mathrm{mEC}$, there are the following two categories of principal cells: stellate and pyramidal neurons (Alonso and Klink, 1993; Canto et al., 2008). Consistent with this, recordings from WT and rTg4510 layer II mECs revealed at least two distinct subtypes of neurons based on their electrophysiological properties. Putative mEC-SCs had a low $R_{i}$, fast membrane time constant $\left(\tau_{\mathrm{M}}\right)$, prominent hyperpolarization-activated cation current $\left(I_{\mathrm{h}}\right)$-mediated sag potential, biphasic afterspike potentials, and a clustered spike firing pattern (Fig. 1), which are properties that are typical of layer II mEC-SCs (Alonso and Klink, 1993; Nolan et al., 2007). In contrast, putative pyramidal neurons had higher $R_{i}$ values, little sag, a monophasic AHP, and a more regular spike firing pattern (Fig. 1). Cells were classed as mEC-SCs if they met all of the following criteria: (1) $R_{i},<125 \mathrm{M} \Omega$; (2) $\tau_{\mathrm{M}}<12 \mathrm{~ms}$; (3) sag, $>25 \%$; and (4) the presence of a biphasic AHP. Using these criteria, the majority of recorded neurons were defined as mEC-SCs (WT mice, 62\%; rTg4510 mice, 63\%), which is consistent with previous estimates of neuronal subtype proportions in the $\mathrm{mEC}$ (Alonso and Klink, 1993; Gatome et al., 2010).

The membrane properties of layer II mEC-SCs at dorsal and ventral locations were recorded from 26 slices from 13 WT mice and 22 slices from $11 \mathrm{rTg} 4510$ mice (7-8 months old). There was no significant effect of location or genotype on RMP (Fig. 2A; Table 1). Since other membrane properties are voltage dependent, cells were subsequently held at a set prestimulus membrane potential of $-80 \mathrm{mV}$ using appropriate levels of steady-state bias current injection. Hyperpolarizing square-wave current steps $(3 \mathrm{~s}, 100 \mathrm{pA})$ resulted in a negative-going voltage deflection with substantial voltage sag. As described previously (Giocomo et al., 2007; Garden et al., 2008; Boehlen et al., 2010; Yoshida et al., 2013), there was a significant main effect of location on $R_{i}$ (cal- 
A
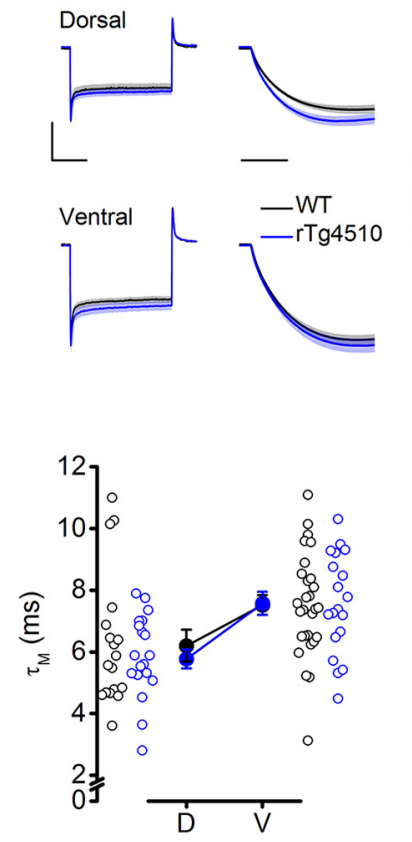

B

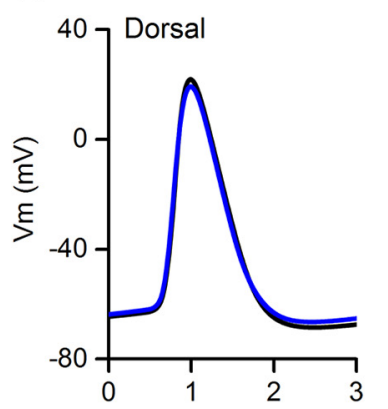

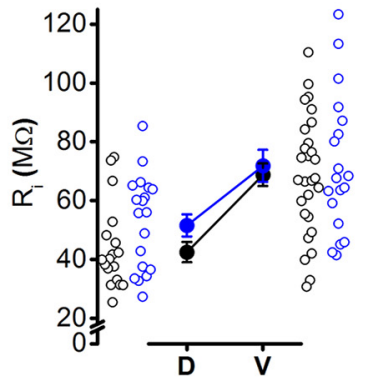
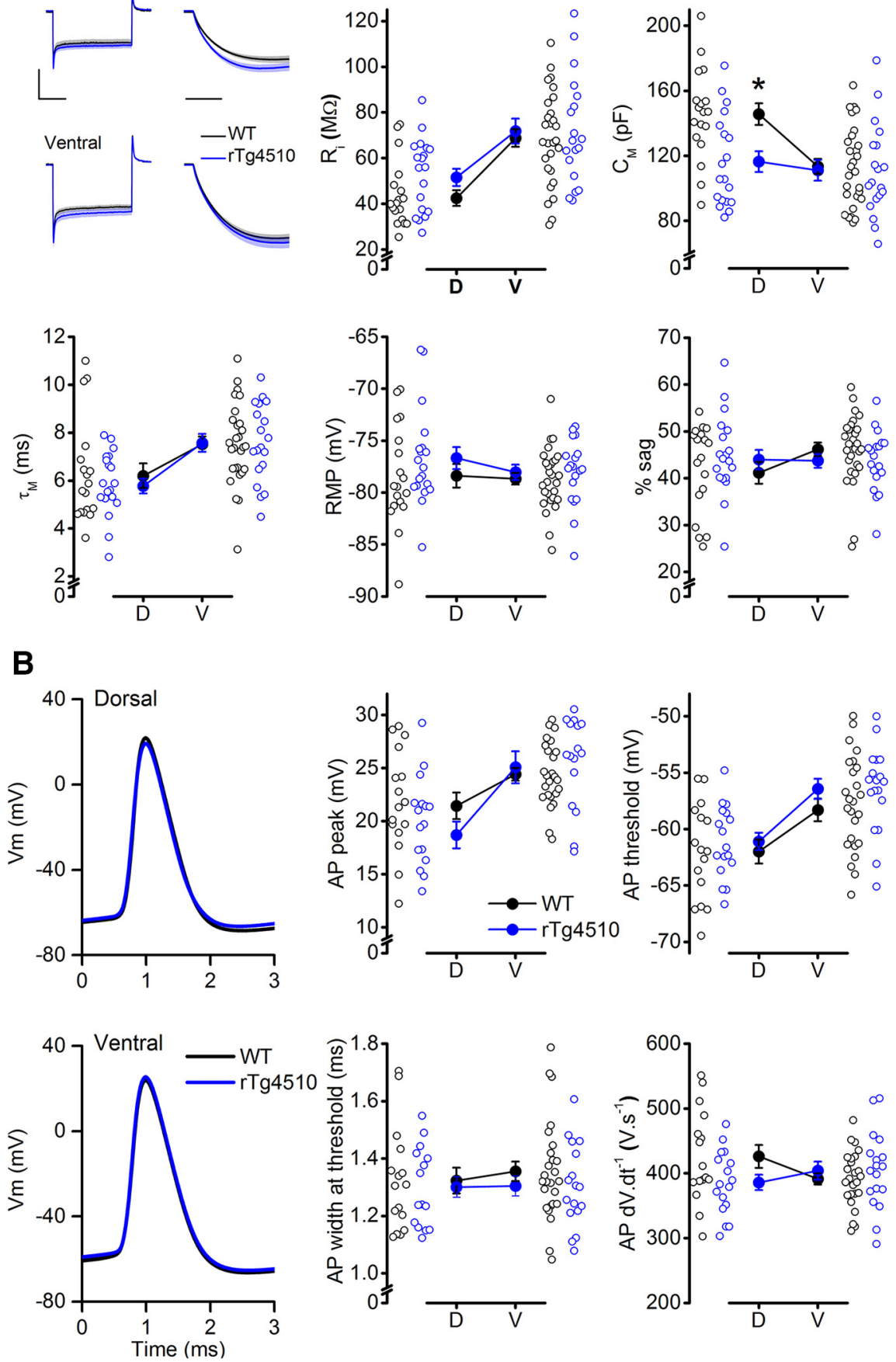

Figure 2. Dorsoventral gradients of intrinsic membrane properties in WT and rTg4510 layer II mEC-SCs.A, Traces are whole-cell current-clamp recordings from layer II mEC-SCS in dorsal (top) or ventral (bottom) locations in WT (black lines) or rTg4510 (blue lines) slices. The traces show the mean ( \pm SEM, shaded areas) voltage response to a $3 \mathrm{~s},-100 \mathrm{pA}$ square-wave current injection from a fixed potential of $-80 \mathrm{mV}$. The inset traces (right) show the initial response on an expanded time scale to illustrate the initial charging curve. Calibration: $1 \mathrm{~s}, 5 \mathrm{mV}$; inset, $10 \mathrm{~ms}$. The scatter plots show $R_{i}, C_{M}, \tau_{M}, R M P$, and the percentage sag from all recorded $m E C-S C S$ at dorsal (D) and ventral (V) locations. Solid symbols are the mean \pm SEM (WT mEC-SCs: D, $n=18 ; \mathrm{V}, n=28$; rTg4510 mEC-SCS: $D, n=19 ; V, n=19$ cells from 13 WT and $11 \mathrm{rTg} 4510$ mice). There was a significant difference in $C_{M}$ in dorsal $\mathrm{mEC}-\mathrm{SCs} .{ }^{*} p<0.05$. $\boldsymbol{B}$, Traces are the mean ( \pm SEM) peak-aligned waveforms of APs recorded from dorsally (top) and ventrally (bottom) located layer II mEC-SCs in WT (black lines) and rTg4510 (blue lines) slices. The analyzed APs were the first of a train elicited by a $0.5-1 \mathrm{nA}$ current injection. The scatter plots show the AP peak, threshold, width at threshold, and maximum rate of rise (dV/dt).

culated from the infinite time extrapolation of single-term exponential fit to the initial charging curve) and $\tau_{\mathrm{M}}$, which were higher and slower in ventral locations, respectively (Fig. 2A; Table 1). However, there was no effect of genotype, and no significant interaction between location and genotype (Table 1). Interestingly, while membrane capacitance $\left(\mathrm{C}_{\mathrm{M}}\right)$ of WT mEC-SCs was higher in dorsal versus ventral locations, this was not the case for $\mathrm{r} \operatorname{Tg} 4510$ mEC-SCs with $\mathrm{C}_{\mathrm{M}}$ in both locations in a manner similar to that in ventral WT mEC-SCs (Fig. 2A). Statistical analysis revealed a significant main effect of both dorsoventral location and genotype, and a significant location-by-genotype interaction on $\mathrm{C}_{\mathrm{M}}$ (Table 1). The relative magnitude of $I_{\mathrm{h}}$-mediated sag potentials was independent of location in both genotypes and was not different between genotypes (Fig. 2A; Table 1). Similarly, the fast time constant of a double exponential fit to the sag potential $\left(\tau_{\text {sag-fast }}\right)$ was independent of location and genotype (WT dorsal, $37.9 \pm 2.6 \mathrm{~ms}, n=18$; WT ventral, $38.9 \pm 2.4 \mathrm{~ms}, n=28 ;$ rTg 4510 dorsal, $35.7 \pm 3.6 \mathrm{~ms}, n=19 ;$ rTg 410 ventral, $40.5 \pm 1.8 \mathrm{~ms}, n=19$; see Table 1 for statistical analysis).

We next examined the AP waveform properties of dorsal and ventral mEC-SCs. We detected significant main effects of dorsoventral position on AP peak and threshold, whereas AP width and maximum rate of rise were independent of location. Nevertheless, no significant effect of genotype was observed for any of these AP properties (Fig. $2 B$; Table 1$)$.

Afterspike potentials play a critical role in the control of AP firing patterns. For instance, AHPs control the clustering of APs in mEC-SCs (Fransen et al., 2004; Pastoll et al., 2012). High-frequency (50 $\mathrm{Hz}$ ) bursts of 5, 10, 15, 20, or 25 brief, strong current injections ( $2 \mathrm{~ms}, 2 \mathrm{nA})$ resulted in trains of single APs (i.e., one spike per current injection to precisely control the number and timing of spikes) in mEC-SCs, which were followed by mAHPs and slow AHPs (sAHPs; Fig. 3A). The sAHP was relatively small and variable, due to contamination by the mAHP and low signal-to-noise ratio when measuring sub-millivolt potentials. Therefore, we focused our analyses on the mAHP, quantified as the peak negative deflection from the prespiking membrane potential observed in the first $100 \mathrm{~ms}$ following the cessation of the last AP. mAHP amplitude was significantly enhanced by increasing the number of spikes in a train $(F=54.9$, $p<0.001$, repeated-measures ANOVA; WT mice: $n=15$ dorsal, $n=24$ ventral; rTg4510 mice: $n=17$ dorsal, $n=18$ ventral; Fig. $3 A, B)$. There was a striking dorsoventral gradient in mAHP amplitude in WT mEC-SCs (dorsal < ventral; Fig. $3 A, B$ ). However, in rTg $4510 \mathrm{mEC}-\mathrm{SCs}$, this gradient was entirely absent, with mAHP amplitudes in dorsal rTg4510 mEC-SCs greater than 
Table 1. Statistical analyses of membrane properties of WT and rTg4510 mEC-SCs at different dorsoventral locations

\begin{tabular}{|c|c|c|c|c|c|c|}
\hline & \multicolumn{2}{|c|}{ Location } & \multicolumn{2}{|c|}{ Genotype } & \multicolumn{2}{|c|}{$\begin{array}{l}\text { Location-by- } \\
\text { genotype }\end{array}$} \\
\hline & $F$ & $p$ & $F$ & $p$ & $F$ & $p$ \\
\hline \multicolumn{7}{|l|}{ Subthreshold properties } \\
\hline RMP & 0.9 & 0.3 & 1.9 & 0.2 & 0.4 & 0.5 \\
\hline$R_{i}$ & 29.8 & $<0.001^{* *}$ & 2.0 & 0.2 & 0.5 & 0.5 \\
\hline$\tau_{\mathrm{M}}$ & 16.5 & $<0.001^{* *}$ & 0.2 & 0.6 & 0.4 & 0.5 \\
\hline$C_{M}$ & 9.8 & $<0.005^{* *}$ & 6.9 & $0.01^{*}$ & 5.0 & $0.03^{*}$ \\
\hline$\%$ Sag & 1.7 & 0.2 & 0.01 & 0.9 & 2.1 & 0.2 \\
\hline $\begin{array}{c}\tau_{\text {sag-fast }} \\
\text { AP properties }\end{array}$ & 1.2 & 0.3 & 0.02 & 0.9 & 0.5 & 0.5 \\
\hline Peak & 16.9 & $<0.001^{* *}$ & 0.8 & 0.4 & 2.2 & 0.1 \\
\hline Threshold & 17.8 & $<0.01^{*}$ & 2.0 & 0.2 & 0.2 & 0.6 \\
\hline Width at threshold & 0.2 & 0.6 & 0.9 & 0.3 & 0.1 & 0.7 \\
\hline Maximum dV/dt & 0.4 & 0.5 & 1.1 & 0.3 & 4.3 & 0.04 \\
\hline \multicolumn{7}{|l|}{ After potentials } \\
\hline mAHP amplitude & 9.1 & $<0.005^{* *}$ & 6.4 & $0.01^{*}$ & 9.4 & $<0.005^{* *}$ \\
\hline
\end{tabular}

Data are two-way repeated-measures ANOVA: F and $p$ values for main effects of location and genotype and locationby-genotype interaction. For passive and AP properties analyses: WT: dorsal, $n=18$; ventral, $n=28$; $r$ Tg4510: dorsal, $n=19$; ventral, $n=19$. For AHP analyses: WT: $n=15$ dorsal, 24 ventral; $r T g 4510: n=17$ dorsal, 18 ventral. ${ }^{*} p<0.05,{ }^{* *} p<0.005$, statistically significant.

in WT neurons and similar to mAHP amplitudes in ventral mECSCs of both genotypes (Fig. $3 A, B$ ). Thus, there was a significant interaction between location and genotype, and significant overall effects of both location and genotype on mAHP amplitude (Table 1).

These data suggest that, in terms of certain neurophysiological features, the dorsal aspect of the mEC is preferentially affected in rTg4510 mice. What are the consequences of aberrant neuronal excitability in the dorsal mEC? AHPs in mEC-SCs control the timing of individual spikes relative to each other; for example, shorter mAHPs in dorsal mEC-SCs contribute to increased spike clustering in these cells relative to ventral $\mathrm{mEC}-\mathrm{SCs}$, which have more prolonged mAHPs (Pastoll et al., 2012). To assess the effects of the altered mAHP in dorsal rTg4510 mEC-SCs, we recorded spontaneous AP firing, by depolarizing a subset of cells (using a constant current injection 1-3 times rheobase), such that regular discharges were observed. In WT dorsal mEC-SCs, the mean $p_{\text {Clus }}$ was higher $(0.69 \pm$ $0.08, n=8)$ than in ventral regions $(0.55 \pm 0.07, n=22)$, but this was not significant ( $p=0.3$, independent-samples Mann-Whitney $U$ test). However, APs recorded from dorsal mEC-SCs in rTg4510 slices had a significantly lower $p_{\text {Clus }}(0.37 \pm 0.12, n=11 ; p<0.05$, independent-samples Mann-Whitney $U$ test), than dorsal WT neurons (Fig. 3C,D). In contrast, spikes recorded from rTg4510 ventral mEC-SCs had a similar $p_{\text {Clus }}$ to WT cells $(0.54 \pm 0.09, n=14 ; p=$ 0.9 , independent-samples Mann-Whitney $U$ test; Fig. $3 C, D$ ). Analysis of mAHP half-widths following these spikes in WT mice revealed shorter mAHP durations in dorsal mEC-SCs $(86 \pm 27 \mathrm{~ms}$, $n=13$ ) compared with ventral mEC-SCs (228 $\pm 71 \mathrm{~ms}, n=23$; $p<$ 0.05 , independent-samples Mann-Whitney $U$ test), which is in agreement with previous studies examining dorsoventral gradients in mAHP duration (Boehlen et al., 2010; Navratilova et al., 2012; Pastoll et al., 2012; Yoshida et al., 2013). However, while we found that ventral WT and rTg4510 neurons had similar mAHP halfwidths (rTg4510 neurons, $282 \pm 68 \mathrm{~ms}, n=14 ; p=0.2$, independent-samples Mann-Whitney $U$ test), dorsal rTg4510 mAHP half-widths were significantly longer (372 $\pm 118 \mathrm{~ms} ; p<$ 0.05, independent-samples Mann-Whitney $U$ test; Fig. 3D) than their WT counterparts, which may contribute to the lower $p_{\text {Clus }}$ observed in these cells.

We next explored the preferential hypoexcitability of the dorsal rTg4510 mEC at a neuronal network level. Gamma frequency band $(30-80 \mathrm{~Hz})$ oscillations are an emergent property of neuronal networks, including the EC (Chrobak and Buzsáki, 1998), and play a critical role in the timing of neural firing. Gamma oscillations can be recorded in mEC slices (Cunningham et al., 2003), the properties of which vary along the dorsoventral axis (Beed et al., 2013). We simultaneously recorded gamma frequency oscillations (induced by continuous bath application of $500 \mathrm{~nm}$ kainate) in dorsal and ventral ends of mEC slices. In WT slices, the maximum spectral frequency (peak at $\sim 15$ min after drug application) of gamma oscillations was significantly faster in the dorsal $(59.0 \pm 1.4 \mathrm{~Hz})$ versus the ventral $(55.6 \pm 1.5 \mathrm{~Hz}, n=$ 12 ; $p<0.05$, paired $t$ test) region of the mEC. Furthermore, as described previously (Beed et al., 2013), the maximal power of gamma oscillations was significantly higher in the dorsal $(-20.7 \pm 1.6 \mathrm{~dB})$ versus the ventral $(-25.8 \pm 1.4 \mathrm{~dB}, n=12 ; p<$ 0.05 , paired $t$ test) $\mathrm{mEC}$ (Fig. 4 ). In contrast, in $\mathrm{rTg} 4510$ slices, there was no difference in maximal gamma frequency in the dor$\operatorname{sal}(53.0 \pm 1.4 \mathrm{~Hz})$ and ventral $(53.2 \pm 1.1 \mathrm{~Hz}, n=18 ; p=0.7$, paired $t$ test) mECs. With regard to gamma power, a dorsoventral gradient was detected in rTg4510 slices, but the direction was reversed such that gamma oscillations in the dorsal mEC were smaller in magnitude that those in the ventral $\mathrm{mEC}$, as follows: dorsal power, $-32.4 \pm 1.0 \mathrm{~dB}$; ventral power, $-29.0 \pm 0.8 \mathrm{~dB}$ $(n=18 ; p<0.05$, paired $t$ test; Fig. 4$)$. As observed for intrinsic neuronal properties, network-level differences between genotypes were evident in the dorsal $\mathrm{mEC}$, but not in the ventral $\mathrm{mEC}$ (Fig. 4D).

Gamma oscillations are driven by local networks of reciprocally connected interneurons. Fast-spiking PV-positive interneurons are thought to play a key role in the generation of gamma oscillations in the entorhinal cortex (Cunningham et al., 2003; Beed et al., 2013). PV immunoreactivity also follows a dorsoventral gradient (greater expression in dorsal vs ventral), which correlates with the extent of inhibitory innervation and gamma oscillation power (Beed et al., 2013). Given this, we sought to establish whether alterations in differential PV expression could account for the deficits in dorsal mEC gamma oscillations. We used an antibody directed against PV on sagittal mEC sections from WT and rTg4510 mice, and subsequently subdivided the resulting light microscopy images into four regions of interest in each layer running along the dorsoventral axis (Fig. 5). As reported previously (Beed et al., 2013), we observed a striking dorsoventral gradient in PV staining in WT sections, both in layer II and III. Importantly, we also identified a similar gradient in rTg4510 sections that was not significantly different from that in WT sections (Fig. 5). Thus, a repeated-measures ANOVA revealed a significant main effect of dorsoventral location in both layer II $(F=39.8, p<0.001)$ and layer III $(F=25.0, p<0.001)$, but no effect of genotype (layer II, $F=0.3, p=0.6$; layer III, $F=$ $0.4, p=0.5 ; n=5$ WT mice, $n=5$ rTg4510 mice). Furthermore, there was no interaction between location and genotype in either layer (layer II, $F=1.2, p=0.3$; layer III, $F=0.2, p=0.7 ; n=5$ both genotypes). These data suggest that changes to the gradient of PV cell number are not responsible for alterations in gamma oscillations in the dorsal mEC.

We next examined whether a differential expression of tau pathology led to the electrophysiological alterations observed in the dorsal mEC. Sections were stained using an antibody specific for PG5 and analyzed in the same manner as the PV staining. As expected, WT sections were essentially negative for PG5 staining, while rTg4510 slices expressed high levels of tau pathology throughout the mEC (Fig. 5). In layer II, there was a significant main effect of genotype $(F=634.8, p<0.001)$, but no main effect 

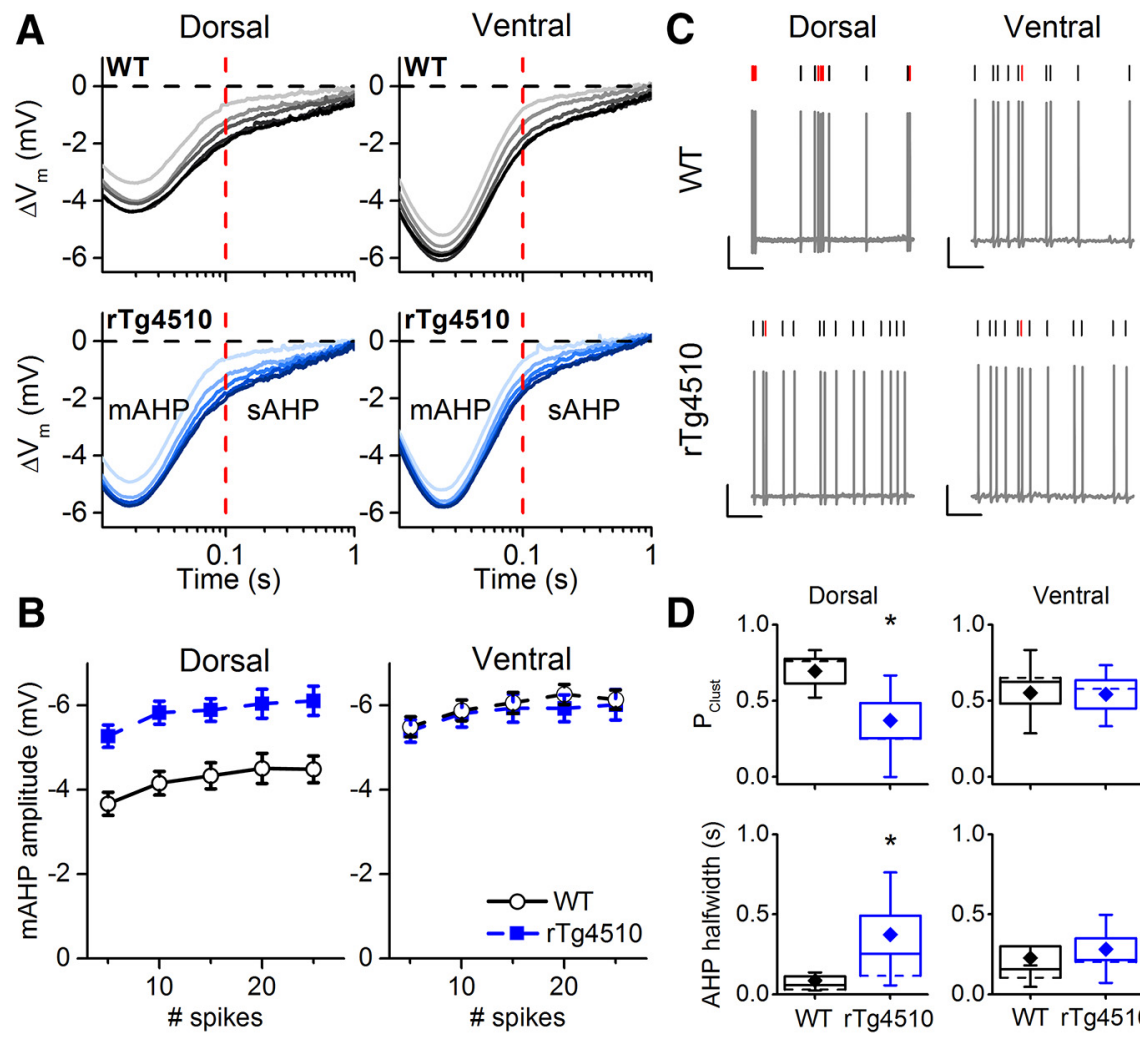

Figure 3. Dorsoventral gradient in mAHP magnitude is abolished in rTg4510 layer II mEC-SCS. A, Average waveforms of AHPs elicited by a train of 5, 10, 15, 20, or 25 APs (lighter through to darker waveforms, respectively) evoked by brief, strong $(2 \mathrm{~ms}, 2 \mathrm{nA}$ ) current injections delivered at $50 \mathrm{~Hz}$. AHPs are plotted on a log-time axis to differentiate the mAHP and sAHP, respectively. The mAHP detection window was up to $0.1 \mathrm{~s}$ after the end of AP firing (dotted red line). The dotted black line represents the pre-AP membrane potential. Recordings were made at a fixed membrane potential of $-80 \mathrm{mV}$. Note the significantly larger mAHP in dorsal mEC-SCs recorded from rTg4510 slices. $\boldsymbol{B}$, Graphs show the mean ( \pm SEM) mAHP amplitude in WT and $\mathrm{rTg} 4510 \mathrm{mEC}-\mathrm{SC}$. A repeated-measures ANOVA revealed a significant main effect of AP number $(F=$ $54.9, p<0.001)$, as well as significant main effects of dorsal-ventral location and genotype, and a significant locationby-genotype interaction (Table 1). C, Representative traces showing the steady-state firing patterns in dorsal and ventral WT and rTg4510 layer II mEC-SCs. Raster plots show the timing of spikes; spikes occurring in a cluster are shown in red. Calibration: $20 \mathrm{mV}, 2$ s. D. Box plots showing the mean (filled diamonds) \pm SEM (solid box lines) $p_{\text {Clus }}$ and mAHP halfwidths. The error bars show the interquartile range, and the dotted horizontal line is the median. Dorsal rTg4510 mEC-SCs are significantly less likely to fire spikes in a cluster and have a significantly longer mAHP half-width when compared with WT counterparts. ${ }^{*} p<0.05$ (independent-samples Mann-Whitney $U$ test).

of location $(F=2.1, p=0.2)$; nor was there a significant interaction between location and genotype $(F=2.1, p=0.2, n=5$ both genotypes). In layer III, again there was a main effect of genotype $(F=107.9, p<0.001)$, but, interestingly, there was a subtle effect of location in this layer $(F=3.5, p=0.03)$ and a significant location-by-genotype interaction $(F=3.5, p=0.03)$. Intriguingly, the slope of this gradient was such that ventral regions of layer III of the mEC expressed slightly higher levels of tau pathology than dorsal regions (Fig. 5).

Brain slice pharmacological models are useful approaches to explore the cellular and pharmacological bases of neuronal network oscillations; however, they do not entirely recapitulate the oscillatory activity observed in vivo. For instance, pharmacologically induced gamma oscillations, such as those presented above, are often observed continuously, whereas, in vivo, gamma frequency oscillation power in the hippocampus and entorhinal cortex is coupled to a specific phase of an ongoing theta oscillation (Chrobak and Buzsáki, 1998; Colgin et al., 2009). To examine whether the alterations in gamma frequency network oscillations observed in $\mathrm{mEC}$ slices translate to equivalent network disruptions in vivo, we implanted multielectrode linear arrays into layer II/III of the mECs of WT and

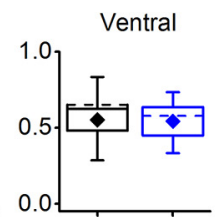

rTg4510 mice. These probes contained 16 recording sites (150 $\mu \mathrm{m}$ apart, linearly arranged on a single shank), which were implanted such that at least 10 recording sites ventral to the postrhinal border were positioned along the dorsal-ventral axis of the $\mathrm{mEC}$ (as determined by post hoc histological analysis; Fig. 6A). Following a postsurgery recovery period, mice were tethered to a multichannel recording system and allowed to explore a novel linear track, and LFP data were analyzed from epochs where mice were running at a constant speed $(10-15 \mathrm{~cm} / \mathrm{s})$.

Broadband spectral power was significantly reduced in $\mathrm{rTg} 4510$ mice along the entire dorsal-ventral axis of the mEC compared with WT (WT, total power $45.9 \pm 1.8 \mathrm{~dB}, n=3$; rTg4510 total power $34.0 \pm 1.5 \mathrm{~dB}, n=5 ; p<$ 0.01 , unpaired $t$ test; Fig. $6 A, B)$, similar to previous observations in the CA1 region of the hippocampus (Cheng and Ji, 2013). Absolute power was decreased in both the theta $(4-12 \mathrm{~Hz})$ and gamma $(30-120 \mathrm{~Hz})$ frequency bands (theta: WT, $43.9 \pm 1.9 \mathrm{~dB}$; rTg4510, $29.4 \pm 1.8$ $\mathrm{dB} ; p<0.01$, unpaired $t$ test; gamma: WT, $37.6 \pm 1.4 \mathrm{~dB}$; rTg4510, $28.0 \pm 2.0$ $\mathrm{dB} ; p<0.05$, unpaired $t$ test; Fig. $6 B)$.

In WT mECs in vivo, gamma frequency oscillations were nested within the theta frequency rhythm (Fig. 6A), as has been previously reported (Chrobak and Buzsáki, 1998). Therefore, to accurately determine the magnitude of gamma oscillations along the dorsal-ventral axis of the $\mathrm{mEC}$, we calculated the extent of crossfrequency coupling and plotted the resulting comodulograms. A quantitative analysis of these data revealed a peak in the theta modulation of gamma power that was evident in the pooled comodulograms (peak modulating frequency, $9.1 \pm 0.2 \mathrm{~Hz}$; peak modulated frequency, $66.3 \pm 0.2 \mathrm{~Hz}$, mean across all recording locations in the mEC; Fig. $6 C)$. There was a clear gradient in the magnitude of theta-gamma cross-frequency coupling along the dorsal-ventral axis of the $\mathrm{mEC}$ in WT mice, such that higher levels of theta-gamma coupling were observed at dorsal electrodes compared with ventral electrodes (Fig. $6 C, D)$. Regression analysis revealed a linear correlation between probe location (relative to the most dorsal probe) and MI in WT mice (slope, $-68.3 \pm 16.3 \mathrm{MI} / \mu \mathrm{m} ; z=2.2 \pm 0.2 ; n=3$; Fig. $6 E$ ). In rTg4510 mice, the absolute magnitude of theta-gamma coupling was significantly reduced across all electrodes when compared with WT mice (Fig. 6C; WT mean MI, $25 \pm 0.1 \times 10^{4}$; rTg4510 mean MI, $2.0 \pm$ $0.3 \times 10^{4} ; p<0.001$, unpaired $t$ test), which likely reflects the overall reduction in broadband LFP power. Furthermore, the gradient in crossfrequency coupling was significantly reduced in rTg4510 mice (slope, $18.2 \pm 11.6 \mathrm{MI} / \mu \mathrm{m} ; z=0.9 \pm 0.2 ; n=5, p<0.05$, unpaired $t$ test compared with WT; Fig. $6 D, E$ ), suggesting that theta-coupled gamma oscillations in rTg4510 mice were similar across different locations along the dorsoventral axis of the mEC (Fig. $6 F$ ).

Changes to the power of theta-coupled gamma network oscillations may come about as a result of the substantial levels of gross 
neurodegeneration that are known to occur in this mouse model (Ramsden et al., 2005; Santacruz et al., 2005; Spires et al., 2006). Indeed, this is the likely explanation for the overall decrease in broadband power along the dorsoventral axis (Fig. 6B). This raises the possibility that dorsal regions of the mEC degenerate in a preferential manner, leading to a flattening of the dorsoventral gradient in network oscillations. To address this possibility, we performed a quantitative assessment of cortical thickness and cell density in cresyl violet-stained parasagittal sections (6 $\mu \mathrm{m}$ thick; Fig. $7 A$ ). The dorsalventral extent of the mEC in WT sections was $2.8 \pm 0.03 \mathrm{~mm}$ in length (range, $2.68-$ $2.86 \mathrm{~mm}$ ), whereas in rTg4510 sections the $\mathrm{mEC}$ was significantly shorter $(2.5 \pm 0.04$ $\mathrm{mm}$; range, $2.40-2.65 \mathrm{~mm}$; $p<0.01$, unpaired $t$ test). Therefore, we measured the thickness of the $\mathrm{mEC}$ in $0.5 \mathrm{~mm}$ increments between 0 and $2 \mathrm{~mm}$ ventral to the postrhinal cortex border (for illustration, see Fig. $7 A$ ). In WT sections, the mEC became progressively thinner down the dorsoventral axis, such that at the most dorsal point it was $693 \pm 15 \mu \mathrm{m}$ from the edge of layer I to the edge of the white matter separating the $\mathrm{mEC}$ from the hippocampus, while at the most ventral aspect ( $2 \mathrm{~mm}$ from dorsal edge) it was $575 \pm 28 \mu \mathrm{m}$ thick (Fig. $7 B$ ). In rTg4510 sections, the mEC also decreased in thickness along the dorsoventral axis; at the dorsal end, it was $617 \pm 16 \mu \mathrm{m}$ thick, while at the most ventral end ( $2 \mathrm{~mm}$ from the dorsal edge) it was $540 \pm 36 \mu \mathrm{m}$ thick. The rTg4510 mEC was significantly thinner than in WT littermates; thus, there was a significant main effect of genotype on cortical thickness ( $F=6.2, p<0.05$, repeatedmeasures ANOVA; $n=5$ for both genotypes). There was also a significant main effect of dorsoventral position on cortical thickness $(F=13.8, p<0.001)$. Importantly, there was no significant interaction between genotype and position $(F=0.8$, $p=0.9$ ), suggesting that, while there were significant levels of cortical degeneration at this age point in rTg4510 mice, this occurred evenly along the dorsoventral axis of the $\mathrm{mEC}$ (Fig. $7 B$ ). Consistent with this, when we plotted the thickness of the rTg4510 mEC as a percentage of the mean WT thickness at different positions along the dorsoventral axis, no significant relationship was observed (Fig. 7B).

Equivalent findings were observed when we examined cell density along the dorsoventral axis of layer II of the mEC (Fig. 7C) with lower overall cell density in rTg4510 sections compared with WT sections $(F=$ $8.5, p<0.05$, repeated-measures ANOVA, main effect of genotype; $n=5$ both groups).

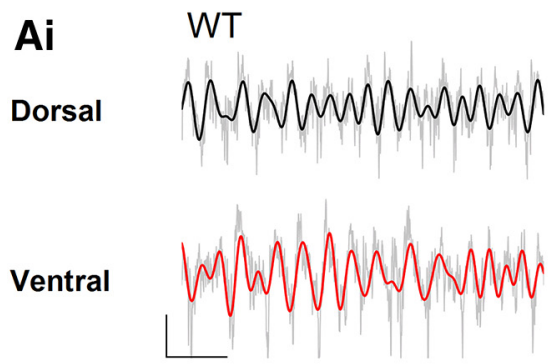

ii $\quad \mathrm{rTg} 4510$

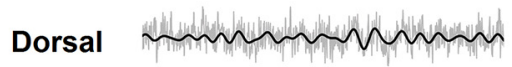

Bi

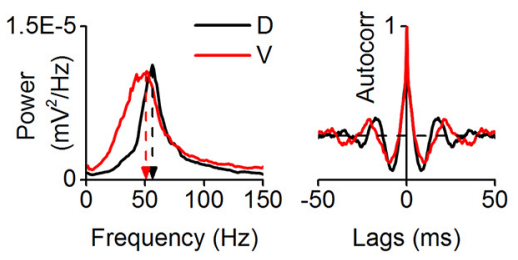

ii
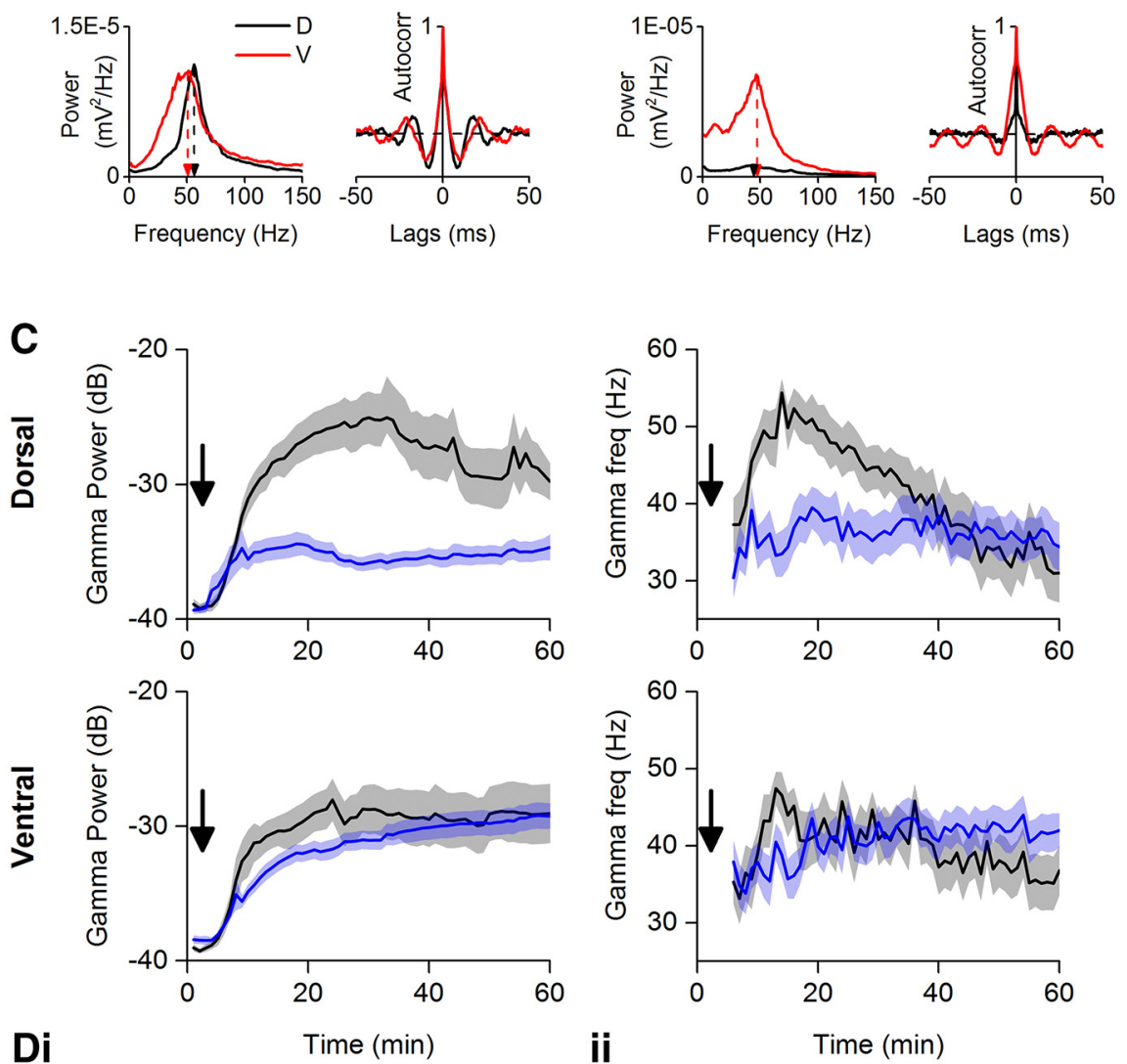

Di

Time $(\min )$
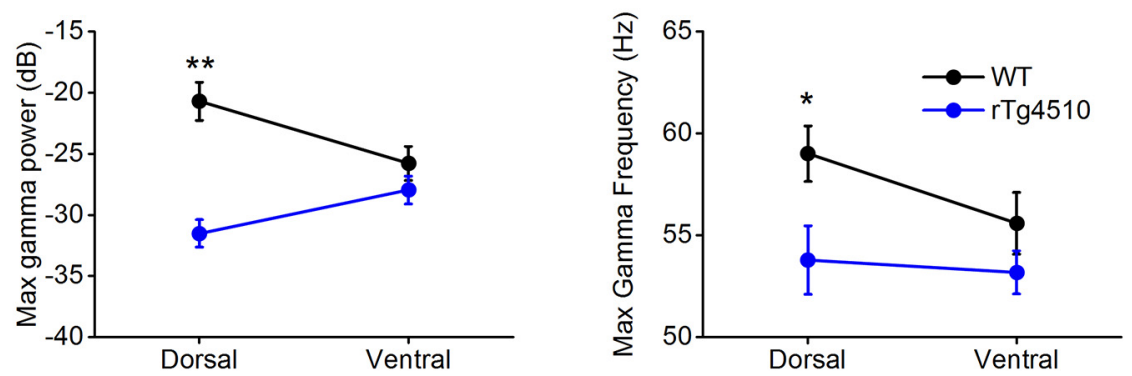

Figure 4. Gamma $(30-80 \mathrm{~Hz})$ oscillations in layer Il of the dorsal, but not ventral, entorhinal cortex are preferentially disrupted in rTg4510 mice. $\boldsymbol{A}$, Traces are simultaneously recorded extracellular gamma oscillations evoked by bath application of $500 \mathrm{~nm}$ kainate in representative WT (Ai) and rTg4510 (Aii) slices. These recordings were made $\sim 15$ min after the start of drug application. Gray traces are raw data; the black (dorsal) and red (ventral) traces are bandpass filtered ( $30-80 \mathrm{~Hz})$. Calibration: $50 \mu \mathrm{V}, 50 \mathrm{~ms}$. $\boldsymbol{B}$, Power spectra and autocorrelograms of the recordings shown in $\boldsymbol{A}$. In WT slices (Bi), gamma oscillations were faster in dorsal (black) versus ventral (red) regions, both in terms of peak spectral frequency and the primary nonzero peak in the autocorrelogram. In rTg4510 slices (Bii), gamma oscillations in the dorsal mEC had significantly reduced power compared with WT slices. C, Pooled time course data showing the development of gamma oscillations following the continuous bath application of kainate (start point is indicated by arrow). Solid lines show the mean ( \pm SEM; shaded areas) gamma power (in dB) and frequency of oscillations in $60 \mathrm{~s}$ bins. D, Summary data showing the maximum gamma power (Di) and frequency (Dii) in WT and rTg4510 slices. Note the selective effects of transgene expression on dorsal gamma oscillations. ${ }^{*} p<0.05,{ }^{* *} p<0.01$. 


\section{WT: PV}

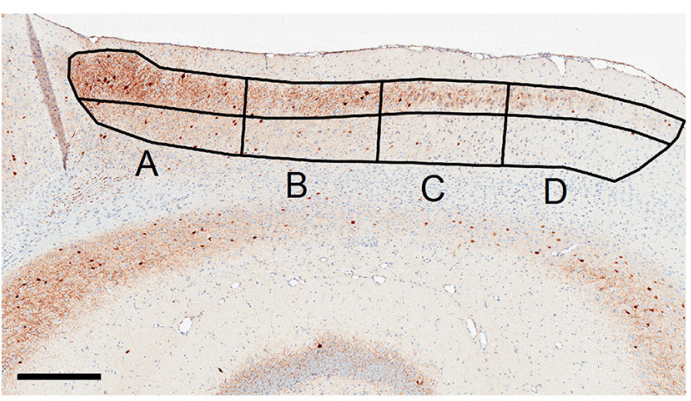

\section{rTg4510: PV}

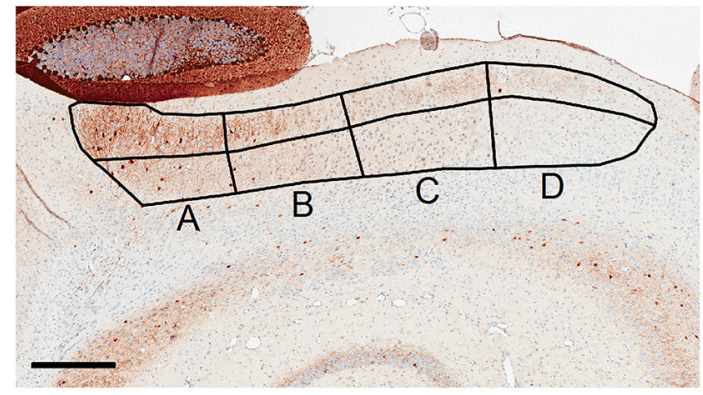

WT: PG5

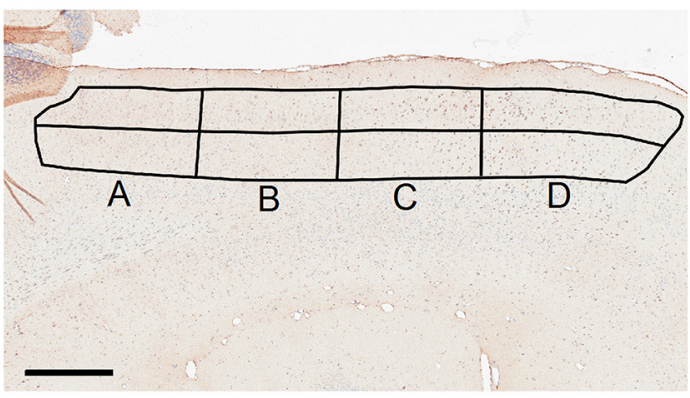

rTg4510: PG5

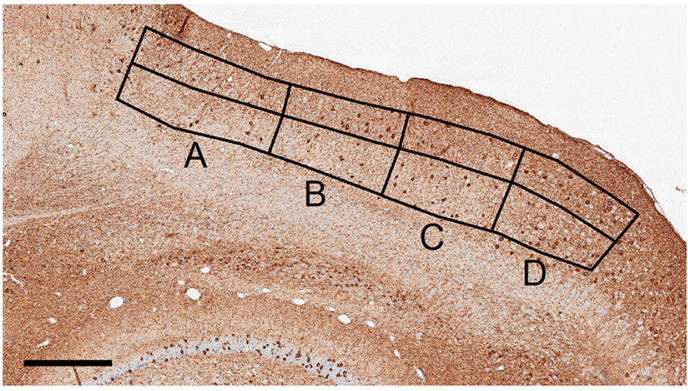

Layer III
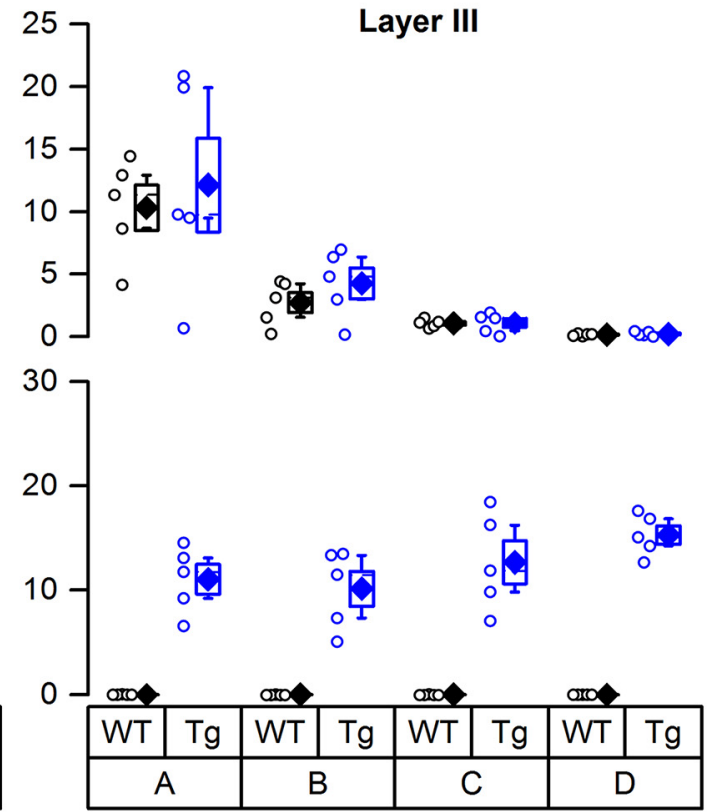

Figure 5. Parvalbumin expression in the $\mathrm{mEC}$ is normal in $\mathrm{rTg} 4510$ mice. Photomicrographs showing representative images of a sagittal section of the $\mathrm{mEC}$ from WT (top) and $\mathrm{rTg} 4510$ (bottom) mice. The images on the left are sections stained with a PV-specific antibody, and the images on the right are sections stained by PG5, an antibody selective for phosphorylated tau. For the purposes of analysis, layers II and III of the $\mathrm{mEC}$ were subdivided into four regions of interest (labeled A-D, where A is most dorsal and D is most ventral). Note the strong gradient in PV staining in both the WT and rTg4510 sections. On the rTg4510 image (bottom left), a lobe of the cerebellum, with extremely dense PV staining is visible. The box plots illustrate the PV (top) and PG5 (bottom) staining in regions A-D in layers II and III in $6 \mu \mathrm{m}$ sections from five WT and five rTg 4510 mice. The mean is denoted by the filled diamonds, the SEM by the solid box lines, the median by the dashed line, and the interquartile range by the whiskers; and open symbols are data from individual mice.

There was a nonsignificant trend of dorsoventral position on cell density in layer II $(F=2.6, p=0.08)$, and, importantly, there was no significant interaction between genotype and position $(F=0.6, p=0.6)$. Finally, in layer III, there was no significant main effect of genotype $(F=1.6, p=0.2$, repeatedmeasures ANOVA, main effect of genotype; $n=5$ both groups), although in this layer there was a main effect of dorsoventral position $(F=3.9, p<0.05)$ on cell density. However, once again there was no significant interaction between these two factors $(F=1.1, p=0.4$; data not shown). Together, these findings suggest that, while there is significant loss of neural tissue in the mEC (particularly in layer II) of rTg4510 mice, the dorsal regions of the $\mathrm{mEC}$ were not selectively vulnerable.

\section{Discussion}

This is the first study to explore dorsoventral gradients in neurophysiological properties of the mEC in a transgenic model of demen- 
A
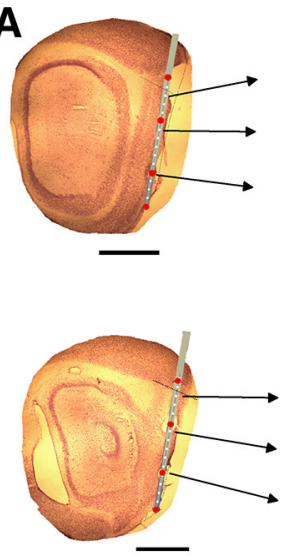

rTg4510
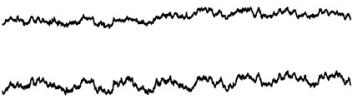

C

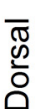

ד্ণ
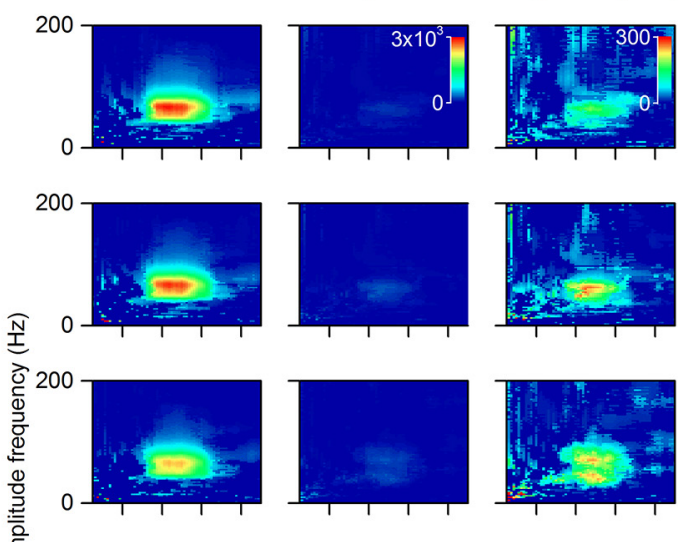

है 200
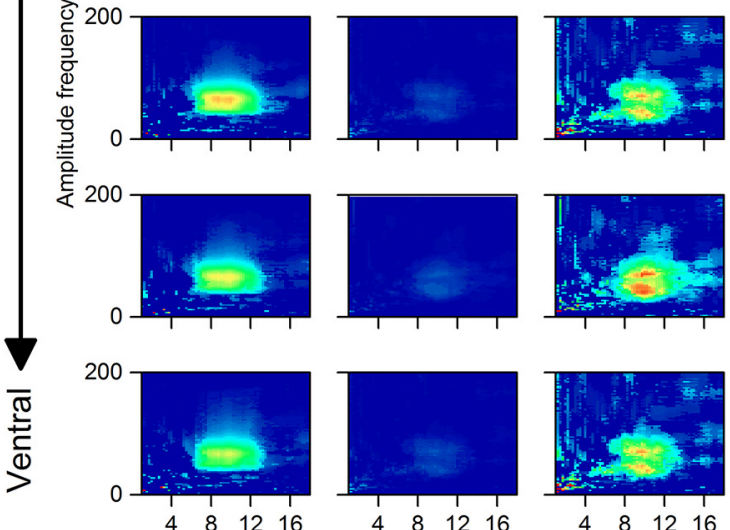

Phase frequency $(\mathrm{Hz}$
B
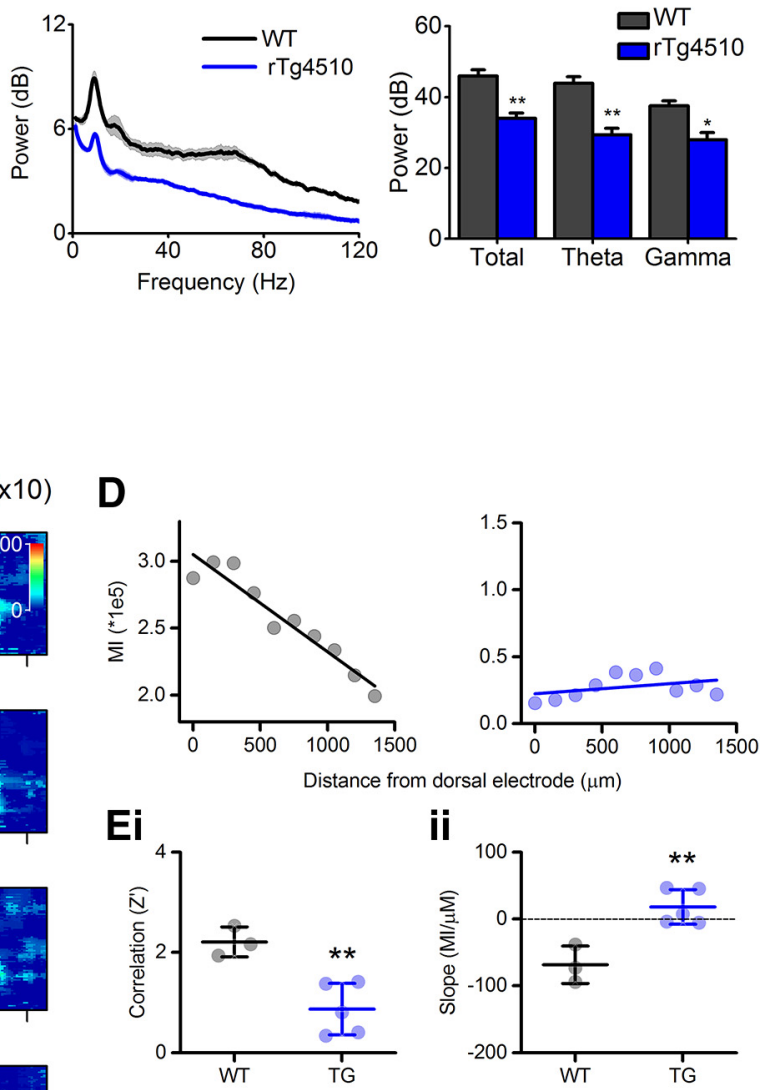

ii

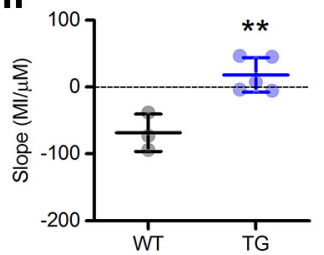

$\mathbf{F}$

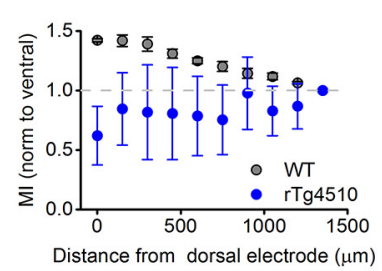

Figure 6. Flattened dorsoventral gradients in gamma-frequency activity in awake behaving $\mathrm{rTg} 4510 \mathrm{mice}$. $A$, Light microscopy images of parasagittal sections through the $\mathrm{mEC}$ of a WT and an rTg4510 mouse, which were implanted with 16-channel linear silicone probes. The position of the probe, as determined by post hoc analysis of the lesion marks (red dots), is shown on each image. Scale bar, $1 \mathrm{~mm}$. Three example LFP recordings are shown to the right of each image, with the location of the recording site illustrated by the arrows. Note the prominent theta oscillation with superimposed gamma frequency oscillations occurring toward the peak of each theta cycle. Calibration: $250 \mathrm{~ms}, 500 \mu \mathrm{V}$. B, Pooled power spectra (mean across all sites within the mEC and then averaged across animals) from epochs of LFP recorded while mice were running at $10-15 \mathrm{~cm} / \mathrm{s}$ (left). Pooled data (right) showing the significant reduction in broadband power (Total) in $\mathrm{rTg} 4510$ mice $(n=5)$ compared with WT mice $(n=3)$, as well as specific reductions in the theta and gamma bands. ${ }^{*} p<0.05,{ }^{* *} p<0.01$. C, Averaged comodulograms showing the extent of theta- gamma cross-frequency coupling along the dorsal (top) to ventral (bottom) axis. Since broadband power is reduced in rTg4510 mice, the right column shows the mean rTg4510 comodulogram with the color scale increased by 10 -fold so that theta- gamma cross-frequency coupling is discernible. $D$, Ml plotted as a function of distance from the most dorsal electrode from example WT (left) and rTg4510 (right) mice. E, Regression analysis reveals a significantly ${ }^{* *} p<0.01$ ) lower z-normalized correlation coefficient (Pearson's $R$; Ei) and slope (Eii) in rTg4510 mice compared with WT mice. Filled circles represent data from each individual animal; the horizontal line is the mean, and the error bars show the SD. $F$, Pooled MI normalized to the most ventral electrode plotted as a function of dorsoventral location.

tia. Our results show that some gradients in intrinsic properties of mEC-SCs are lost while others are preserved in 7- to 8-month-old rTg4510 mice compared with their WT littermates. This is accompanied by a flattening of gradients in oscillatory network properties both in vitro and in vivo in rTg4510 mice. These alterations in cellular and network level properties may underlie the deficits in spatial learning and memory that have been consistently reported in these mice (Ramsden et al., 2005; Santacruz et al., 2005).
Comparison of 7-8 month WT data with existing literature on dorsoventral gradients in mEC neurophysiology

As far as we are aware, the present study is the only one examining dorsal-ventral gradients in mEC neurophysiology in aged animals (7-8 months old). Previous studies have all used considerably younger (2-12 weeks) rats or mice, so it is worthwhile to compare our WT data with the results from these published studies. Some gradients (or lack of) in intrinsic properties of mEC- 

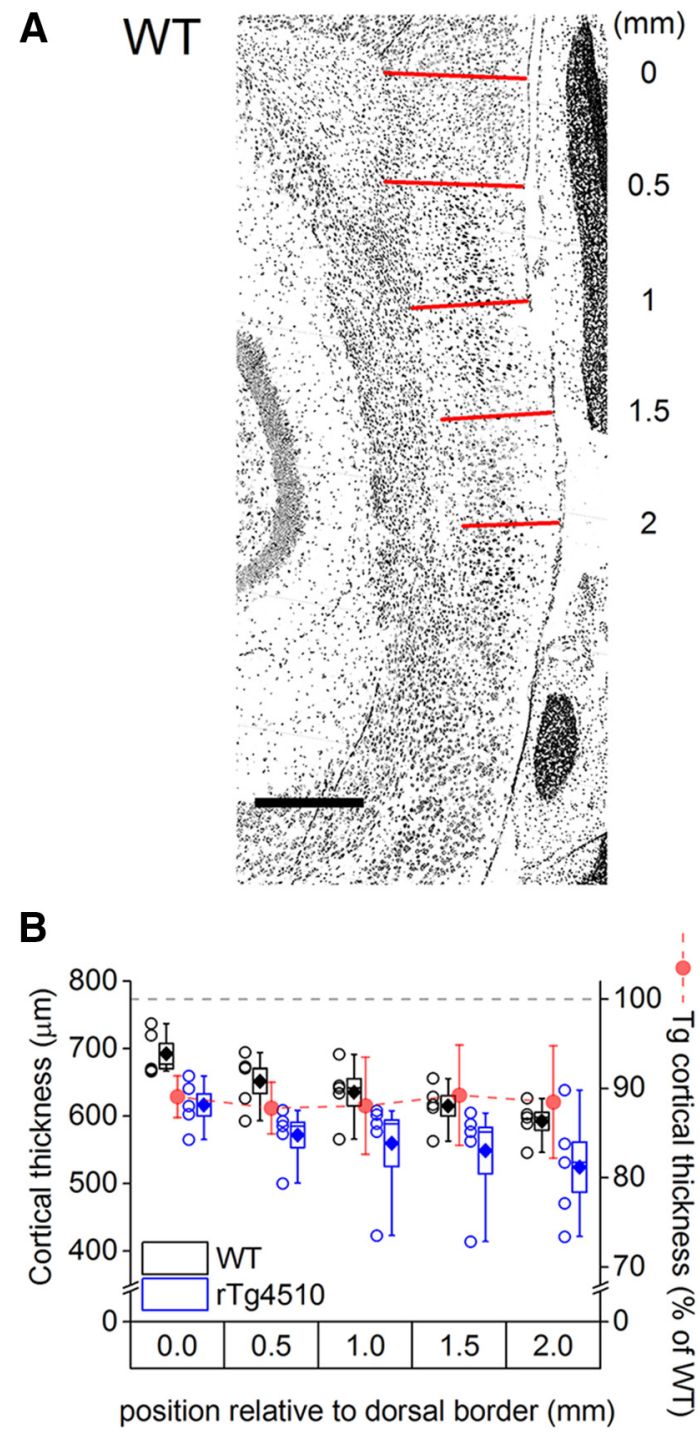

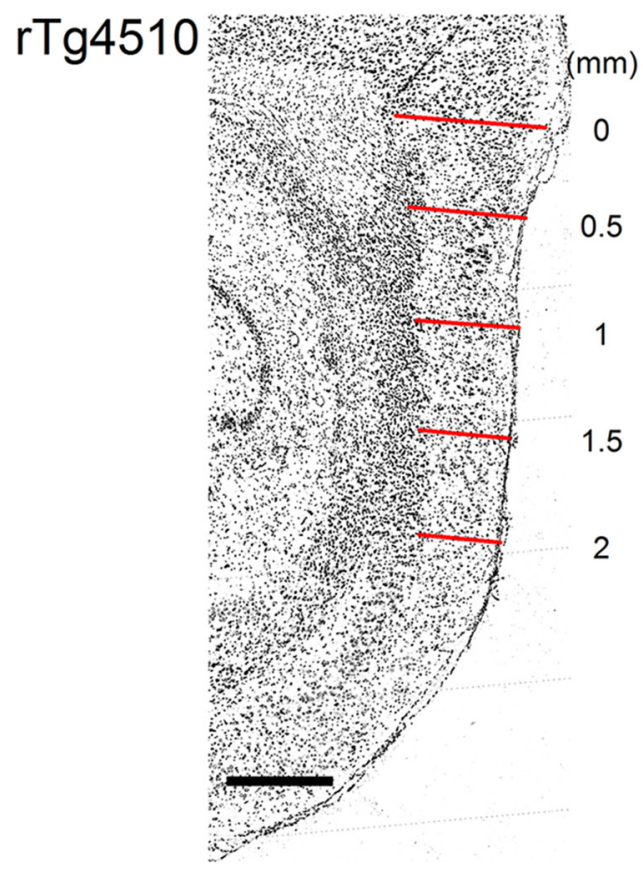

$(\mathrm{mm})$

0

0.5

1

1.5

C

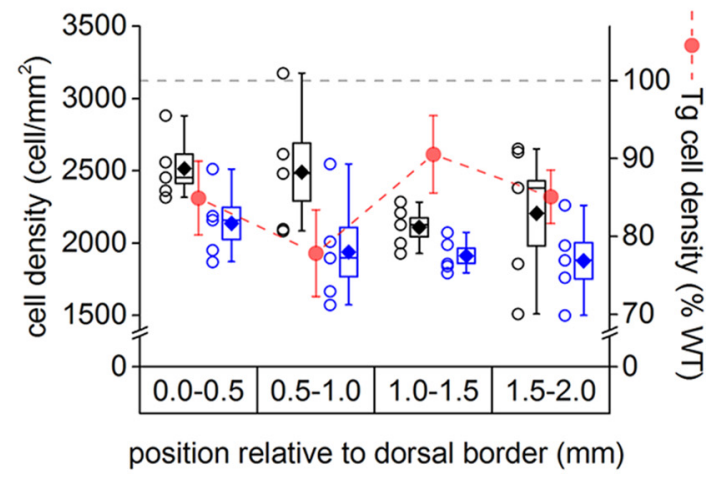

Figure 7. Cortical degeneration occurs evenly along the dorsoventral axis of the $\mathrm{mEC} . A$, Example photomicrographs of cresyl violet-stained sections from a WT (left) and rTg4510 (right) mouse. Lines representing the measurement locations $(0-2 \mathrm{~mm}$ in $0.5 \mathrm{~mm}$ increments) are shown in red. Scale bar, $0.5 \mathrm{~mm}$. $\boldsymbol{B}, \boldsymbol{C}$, Box plots illustrating cortical thickness ( $\boldsymbol{B})$ and cell density in layer II ( $\boldsymbol{C}$ ) in WT $(n=5)$ and rTg4510 $(n=5)$ mice at the points/regions marked in $\boldsymbol{A}$. The open symbols represent the data from sections from individual animals, the filled diamond is the mean, the central line is the median, the box is the SEM, and the whiskers are the interquartile range.

SCs have consistently been reported in younger nontransgenic rats and mice in all studies that have examined them, as follows: (1) RMP is independent of location (Giocomo et al., 2007; Garden et al., 2008; Giocomo and Hasselmo, 2008, 2009; Boehlen et al., 2010; Pastoll et al., 2012); (2) input resistance is higher and membrane time constant is slower in ventral compared with dorsal mEC-SCs (Garden et al., 2008; Boehlen et al., 2010; Pastoll et al., 2012; Yoshida et al., 2013); and (3) mAHP duration increases along the dorsoventral axis of the mEC (Boehlen et al., 2010; Navratilova et al., 2012; Pastoll et al., 2012; Yoshida et al., 2013). Our data from 7- to 8-month-old WT mice are entirely consistent with these well replicated results (Figs. $2 A, 3 D$ ), suggesting that these gradients are preserved with age. A number of studies have also identified dorsoventral gradients in $\mathrm{mEC}-\mathrm{SC}$ intrinsic membrane theta resonance (Giocomo et al., 2007; Giocomo and Hasselmo, 2008, 2009; Boehlen et al., 2010; Heys and Hasselmo, 2012; Pastoll et al., 2012) and subthreshold membrane oscillations (Giocomo et al., 2007; Giocomo and Hasselmo, 2008, 2009; Boehlen et al., 2010; Dodson et al., 2011; Pastoll et al., 2012), although these gradients were not studied here.
Previous studies examining dorsoventral gradients in $I_{\mathrm{h}}$ mediated sag potentials and mAHP amplitudes are less consistent. With regard to $I_{\mathrm{h}}$-mediated sag potentials, two reports have demonstrated a decreasing relative amplitude along the dorsoventral axis (Garden et al., 2008; Giocomo and Hasselmo, 2009), while another did not observe a gradient (Yoshida et al., 2013). Here, we did not detect a gradient in the relative amplitude of $I_{\mathrm{h}}$-mediated sag potentials in WT mice (Fig. 2A). The evidence for a dorsoventral gradient in the kinetics of $I_{\mathrm{h}}$-mediated sag potentials is somewhat more consistent. Two groups agree that the fast time constant of sag potentials is increased in more ventrally located mEC-SCs (Giocomo et al., 2007; Giocomo and Hasselmo, 2008, 2009; and Boehlen et al., 2010). Our data from WT mice revealed no gradient in the fast time constant of sag; however, there is evidence that this gradient degrades somewhat between juvenile and early adult time points. Boehlen et al. (2010) reported a difference of $\sim 11 \mathrm{~ms}$ between dorsal and ventral fast time constants of sag in juvenile rats (2-3 weeks old), which was reduced to $\sim 2 \mathrm{~ms}$ in $\sim 3$-month-old animals. In our 7- to 8-month-old WT mice, the difference (while not significant) was 
$\sim 1 \mathrm{~ms}$, which is similar to that seen in younger adults in the Boehlen et al. (2010) study, raising the possibility that the flattening of the sag time constant gradient continues throughout adulthood, perhaps as a result of experience-dependent plasticity of $I_{\mathrm{h}}$ (Fan et al., 2005). Performing whole-cell recordings in brain tissue from older animals is technically challenging, and, while we were careful to ensure a good level of quality control (see Materials and Methods), it is possible that tissue from older animals responds differently to the slicing process, which in some way alters the ionic mechanisms underlying dorsoventral gradients. An alternative explanation for the lack of gradient in sag time constant is the approach taken: we used a fixed current injection to elicit sag potentials, which, due to the gradient in input resistance, hyperpolarized individual cells to different extents. In itself, the different levels of hyperpolarization may alter sag potential time constants.

Fewer studies have examined dorsoventral gradients in mAHP amplitudes. Yoshida et al. (2013) saw a gradient in mAHP amplitude in juvenile rats (in the opposite direction to the gradient we observed), while Boehlen et al. (2010) could only observe this gradient in juvenile rats (when using patch-clamp but not sharp electrodes), and not at all in young adult rats. While the effect of aging on AHPs in mEC-SCs is not currently known, hippocampal and prefrontal cortical neuron AHPs are known to increase in amplitude during aging (Matthews et al., 2009; Oh et al., 2010; Luebke and Amatrudo, 2012), so it will be interesting to determine whether a dorsoventral gradient in mAHP amplitude appears or is reversed with age as our data from aged WT mice (Fig. $3 A, B$ ) suggest it might be.

Finally, our data from 7- to 8-month-old WT mice also revealed dorsoventral gradients in PV staining (Fig. 5) and gamma oscillations in vitro (Fig. 4), which are in agreement with those from a previous report (Beed et al., 2013). Beed et al. (2013) also identified a clear gradient in the power of gamma frequency oscillations in anesthetized rats in vivo; in agreement with this, we also identified a gradient in theta-coupled gamma power in vivo, although, importantly, we show (for the first time) that such a gradient is also observed in awake, behaving animals.

\section{Alterations in rTg4510 mice compared with WT mice}

Some of the dorsoventral gradients in $\mathrm{mEC}$-SC intrinsic properties that were observed in WT slices appear to be severely attenuated or lost altogether in rTg4510 slices $\left(C_{M}\right.$ and $\mathrm{mAHP}$ amplitude), while others (e.g., $R_{i}, \tau_{\mathrm{M}}$, and AP properties) remain largely unaffected, suggesting that the various dorsoventral gradients do not all arise from a single common source. We identified a selective reduction in (primarily) somatic $\mathrm{C}_{\mathrm{M}}$ in dorsal layer II mEC-SCs in rTg4510 mice, whereas no difference was found in ventral mEC-SCs between WT and rTg4510 mice (Fig. 2 ). The capacitance of a cell is directly proportional to the surface area of the membrane being sampled, so a reduction in $\mathrm{C}_{\mathrm{M}}$ suggests an overall reduction in the size of the neurons in dorsal mEC-SCs. In this regard, Garden et al. (2008) reported a gradient in area and perimeter (size) of the cell body, and in the dendritic complexity of mEC-SCs in nontransgenic mice, which at least partially accounts for the gradient in $\mathrm{C}_{\mathrm{M}}$. Therefore, our data suggest that there are specific changes to neuronal morphology of dorsal mEC-SCs, but not ventral mEC-SCs, in rTg4510 mice. Alterations in dendritic length and complexity in this model of tauopathy have previously been reported in layer III frontal cortical neurons (Rocher et al., 2010; Crimins et al., 2012), suggesting that the overexpression of mutant tau affects neuronal morphology in multiple brain areas. Interestingly, Rocher et al.
(2010) and Crimins et al. (2012) also report an increase in sag potential and a depolarized RMP in rTg4510 layer III frontal cortical neurons, suggesting that changes to intrinsic excitability are a common feature of cortical neurons in this mouse model. However, our recordings of mEC-SCs suggest a different electrophysiological phenotype; in particular, we did not observe any consistent differences in sag potential or RMP (although we have seen the former in CA1 pyramidal neurons; Booth et al., 2016). This may reflect a differential effect on stellate versus pyramidal neurons or alternatively may represent a differential effect in the entorhinal cortex versus the frontal cortex. Importantly, our data suggest that these effects may be region specific, raising the possibility that some aspects of ventral mEC-SCs are resistant to the pathophysiological processes associated with tauopathy.

The dorsoventral gradient in MAHP amplitude was flattened in rTg4510 layer II mEC-SCs, and, as observed for $\mathrm{C}_{\mathrm{M}}$, this was due to differences in dorsal but not ventral mEC-SCs between genotypes (Fig. 3). AHPs play an important role in the control of firing patterns in mEC neurons (Pastoll et al., 2012), and we found that the ability of dorsal mEC-SCs to fire APs in clusters was attenuated in $\mathrm{rTg} 4510$ neurons relative to WT neurons (Fig. 3 ), suggesting that alterations in AHPs in rTg4510 mEC-SCs may have a significant impact on the dorsoventral organization of the output of these neurons. In this respect, we have identified a substantial deficit in gamma frequency network oscillations in dorsal, but not ventral, rTg4510 mEC slices, which may represent a functional consequence of the altered intrinsic properties $\mathrm{mEC}$ SCs (Fig. 4).

Our immunocytochemistry data did not reveal any clear relationship between tau pathology and functional deficits in the dorsal mEC (Fig. 5). Indeed, if anything, we found tau pathology to be slightly, but significantly, more prominent in layer III (but not layer II) of the ventral compared with the dorsal mEC. How, or if, these findings correspond to the clear functional deficits in the dorsal mEC is not clear.

In freely behaving rTg4510 mice, broadband LFP power was substantially reduced across all recording sites along the dorsalventral axis of the mEC compared with WT mice, in a manner consistent with reports in the CA1 region of the hippocampus (Cheng and Ji, 2013), which may reflect the generalized neurodegeneration observed in this model of tauopathy (Ramsden et al., 2005; Santacruz et al., 2005). Our quantitative histological analysis revealed that there were significant levels of neurodegeneration (both in terms of cortical thickness and cell density) in rTg4510 mEC, but that this degeneration was not specific to the dorsal mEC (Fig. 7). Consequently, the observed alterations in theta-gamma coupling cannot be specifically attributed to selective degeneration of the dorsal mEC. In WT mice, we identified a dorsal-ventral gradient in theta-gamma cross-frequency modulation, which likely corresponds to the previously reported gradient in gamma oscillations observed both in vitro and in anesthetized rats in vivo (Beed et al., 2013). Importantly, this gradient was absent in rTg4510 mice (Fig. 6), suggesting that the circuitry responsible for coordinating theta-modulated gamma oscillations was differentially disrupted across the mEC. Evidence from optogenetically driven gamma oscillations in mEC slices suggests that the disruption in theta-gamma cross-frequency coupling might arise from impairment in excitatory drive onto fast-spiking interneurons (Pastoll et al., 2013). Indeed, we have recently reported that glutamatergic drive on to CA1 hippocampal interneurons is defective in rTg4510 mice (Witton et al., 2014), contributing to an emerging picture of the disruption of GABAergic circuits in mouse models of dementia (Driver et al., 
2007; Palop et al., 2007; Baglietto-Vargas et al., 2010; Verret et al., 2012).

This deficit in dorsal mEC gamma-band oscillations was not a result of changes to dorsal mEC PV expression in rTg4510 mice. $\mathrm{PV}$-positive interneurons are thought to provide recurrent inhibition within the mEC (Buetfering et al., 2014) in a manner that may contribute to grid cell formation (Couey et al., 2013). Beed et al. (2013) reported that PV expression was graded along the dorsoventral axis, in a manner that correlated with the extent of inhibitory connectivity and gamma power. In the present study, we also identified a prominent dorsoventral gradient in PV expression in both WT and rTg4510 mice (Fig. 5). Since excitatory synaptic transmission is required for gamma oscillations in the mEC (Cunningham et al., 2003), we propose that disturbances to excitatory stellate neuron firing patterns in the dorsal mEC (Fig. 3 ) contribute to the deficits in gamma-band oscillations in this cortical subregion. Nevertheless, since inhibitory circuits in these regions were not directly studied, it is possible that, while immunhistochemically normal, GABAergic transmission is altered in $\operatorname{rg} 4510$ entorhinal cortex.

\section{Implications for grid/place cells and spatial information processing}

The entorhinal cortex is known to play a key role in the neural representation of geometric space. Lesions (either complete or partial) or pharmacological inactivation of the entorhinal cortex alter spatial representation in the hippocampus, with most studies (Brun et al., 2008; Hales et al., 2014; Ormond and McNaughton, 2015) reporting increased firing field size and reduced spatial information content of CA1 place cells (but see also Van Cauter et al., 2008). When considering our data in the context of such pharmacological or lesion studies, it should be noted that, while rTg4510 mice clearly express a neurodegenerative phenotype that could contribute to hippocampal spatial coding impairment, the extent of cell loss is not nearly as extreme as the functional ablations used in the above studies. Forebrainrestricted genetic ablation of HCN1 channels flattens mEC dorsoventral gradients in some intrinsic neuronal properties, such as subthreshold membrane resonance and theta-frequency oscillations (Giocomo and Hasselmo, 2009), alters the size and spacing of grid cell firing fields (although does not alter the overall gradient in grid cell spacing; Giocomo et al., 2011) and significantly reduces spatial information content of CA1 place cells (Hussaini et al., 2011). Clearly, in these knock-out mice, HCN1 channels are also deleted in the hippocampus (Nolan et al., 2004), which may well affect spatial representation regardless of the effects on entorhinal cortex. Nevertheless, together, these findings indicate that preferential modulation of the intrinsic membrane properties of dorsal mEC in rTg4510 mice, resulting in a flattening of entorhinal dorsoventral gradients, may contribute to disturbances in spatial learning and memory observed in this model of tauopathy (Ramsden et al., 2005), as indeed will the overall levels of neurodegeneration observed within the $\mathrm{mEC}$ and throughout the cortex.

\section{References}

Alonso A, Klink R (1993) Differential electroresponsiveness of stellate and pyramidal-like cells of medial entorhinal cortex layer II. J Neurophysiol 70:128-143. Medline

Amaral DG, Witter MP (1989) The three-dimensional organization of the hippocampal formation: a review of anatomical data. Neuroscience 31: 571-591. CrossRef Medline

Baglietto-Vargas D, Moreno-Gonzalez I, Sanchez-Varo R, Jimenez S, Trujillo-Estrada L, Sanchez-Mejias E, Torres M, Romero-Acebal M,
Ruano D, Vizuete M, Vitorica J, Gutierrez A (2010) Calretinin interneurons are early targets of extracellular amyloid-beta pathology in PS1/ AbetaPP Alzheimer mice hippocampus. J Alzheimers Dis 21:119-132. CrossRef Medline

Beed P, Gundlfinger A, Schneiderbauer S, Song J, Böhm C, Burgalossi A, Brecht M, Vida I, Schmitz D (2013) Inhibitory gradient along the dorsoventral axis in the medial entorhinal cortex. Neuron 79:1197-1207. CrossRef Medline

Boehlen A, Heinemann U, Erchova I (2010) The range of intrinsic frequencies represented by medial entorhinal cortex stellate cells extends with age. J Neurosci 30:4585-4589. CrossRef Medline

Booth C, Witton J, Nowacki J, Tsaneva-Atanasova K, Jones MW, Randall AD, Brown JT (2016) Altered intrinsic pyramidal neuron properties and pathway-specific synaptic dysfunction underlie aberrant hippocampal network function in a mouse model of tauopathy. J Neurosci 36:350-363. CrossRef

Braak H, Braak E (1991) Neuropathological stageing of Alzheimer-related changes. Acta Neuropathol 82:239-259. CrossRef Medline

Brown JT, Chin J, Leiser SC, Pangalos MN, Randall AD (2011) Altered intrinsic neuronal excitability and reduced $\mathrm{Na}(+)$ currents in a mouse model of Alzheimer's disease. Neurobiol Aging 32:2109.e1-e14. CrossRef Medline

Brun VH, Leutgeb S, Wu HQ, Schwarcz R, Witter MP, Moser EI, Moser MB (2008) Impaired spatial representation in CAl after lesion of direct input from entorhinal cortex. Neuron 57:290-302. CrossRef Medline

Buetfering C, Allen K, Monyer H (2014) Parvalbumin interneurons provide grid cell-driven recurrent inhibition in the medial entorhinal cortex. Nat Neurosci 17:710-718. CrossRef Medline

Canolty RT, Edwards E, Dalal SS, Soltani M, Nagarajan SS, Kirsch HE, Berger MS, Barbaro NM, Knight RT (2006) High gamma power is phaselocked to theta oscillations in human neocortex. Science 313:1626-1628. CrossRef Medline

Canto CB, Wouterlood FG, Witter MP (2008) What does the anatomical organization of the entorhinal cortex tell us? Neural Plast 2008:381243. CrossRef Medline

Cheng J, Ji D (2013) Rigid firing sequences undermine spatial memory codes in a neurodegenerative mouse model. Elife 2:e00647. CrossRef Medline

Chrobak JJ, Buzsáki G (1998) Gamma oscillations in the entorhinal cortex of the freely behaving rat. J Neurosci 18:388-398. Medline

Colgin LL, Denninger T, Fyhn M, Hafting T, Bonnevie T, Jensen O, Moser MB, Moser EI (2009) Frequency of gamma oscillations routes flow of information in the hippocampus. Nature 462:353-357. CrossRef Medline

Couey JJ, Witoelar A, Zhang SJ, Zheng K, Ye J, Dunn B, Czajkowski R, Moser MB, Moser EI, Roudi Y, Witter MP (2013) Recurrent inhibitory circuitry as a mechanism for grid formation. Nat Neurosci 16:318-324. CrossRef Medline

Crimins JL, Rocher AB, Peters A, Shultz P, Lewis J, Luebke JI (2011) Homeostatic responses by surviving cortical pyramidal cells in neurodegenerative tauopathy. Acta Neuropathol 122:551-564. CrossRef Medline

Crimins JL, Rocher AB, Luebke JI (2012) Electrophysiological changes precede morphological changes to frontal cortical pyramidal neurons in the rTg4510 mouse model of progressive tauopathy. Acta Neuropathol 124: 777-795. CrossRef Medline

Cunningham MO, Davies CH, Buhl EH, Kopell N, Whittington MA (2003) Gamma oscillations induced by kainate receptor activation in the entorhinal cortex in vitro. J Neurosci 23:9761-9769. Medline

Dodson PD, Pastoll H, Nolan MF (2011) Dorsal-ventral organization of theta-like activity intrinsic to entorhinal stellate neurons is mediated by differences in stochastic current fluctuations. J Physiol 589:2993-3008. CrossRef Medline

Driver JE, Racca C, Cunningham MO, Towers SK, Davies CH, Whittington MA, LeBeau FE (2007) Impairment of hippocampal gamma-frequency oscillations in vitro in mice overexpressing human amyloid precursor protein (APP). Eur J Neurosci 26:1280-1288. CrossRef Medline

Fan Y, Fricker D, Brager DH, Chen X, Lu HC, Chitwood RA, Johnston D (2005) Activity-dependent decrease of excitability in rat hippocampal neurons through increases in I(h). Nat Neurosci 8:1542-1551. CrossRef Medline

Fransen E, Alonso AA, Dickson CT, Magistretti J, Hasselmo ME, Fransen E, Alonso AA, Dickson CT, Magistretti J, Hasselmo ME, Fransen E, Alonso AA, Dickson CT, Magistretti J, Hasselmo ME (2004) Ionic mechanisms 
in the generation of subthreshold oscillations and action potential clustering in entorhinal layer II stellate neurons. Hippocampus 384:368-384. CrossRef Medline

Fyhn M, Molden S, Witter MP, Moser EI, Moser MB (2004) Spatial representation in the entorhinal cortex. Science 305:1258-1264. CrossRef Medline

Fyhn M, Hafting T, Witter MP, Moser EI, Moser MB (2008) Grid cells in mice. Hippocampus 18:1230-1238. CrossRef Medline

Garden DL, Dodson PD, O’Donnell C, White MD, Nolan MF (2008) Tuning of synaptic integration in the medial entorhinal cortex to the organization of grid cell firing fields. Neuron 60:875-889. CrossRef Medline

Gatome CW, Slomianka L, Lipp HP, Amrein I (2010) Number estimates of neuronal phenotypes in layer II of the medial entorhinal cortex of rat and mouse. Neuroscience 170:156-165. CrossRef Medline

Giocomo LM, Hasselmo ME (2008) Time constants of h current in layer II stellate cells differ along the dorsal to ventral axis of medial entorhinal cortex. J Neurosci 28:9414-9425. CrossRef Medline

Giocomo LM, Hasselmo ME (2009) Knock-out of HCN1 subunit flattens dorsal-ventral frequency gradient of medial entorhinal neurons in adult mice. J Neurosci 29:7625-7630. CrossRef Medline

Giocomo LM, Zilli EA, Fransén E, Hasselmo ME (2007) Temporal frequency of subthreshold oscillations scales with entorhinal grid cell field spacing. Science 315:1719-1722. CrossRef Medline

Giocomo LM, Hussaini SA, Zheng F, Kandel ER, Moser MB, Moser EI (2011) Grid cells use HCN1 channels for spatial scaling. Cell 147: 1159-1170. CrossRef Medline

Hafting T, Fyhn M, Molden S, Moser MB, Moser EI (2005) Microstructure of a spatial map in the entorhinal cortex. Nature 436:801-806. CrossRef Medline

Hales JB, Schlesiger MI, Leutgeb JK, Squire LR, Leutgeb S, Clark RE (2014) Medial entorhinal cortex lesions only partially disrupt hippocampal place cells and hippocampus-dependent place memory. Cell Rep 9:893-901. CrossRef Medline

Heys JG, Hasselmo ME (2012) Neuromodulation of $I_{\mathrm{h}}$ in layer II medial entorhinal cortex stellate cells: a voltage-clamp study. J Neurosci 32: 9066-9072. CrossRef Medline

Hoover BR, Reed MN, Su J, Penrod RD, Kotilinek LA, Grant MK, Pitstick R, Carlson GA, Lanier LM, Yuan LL, Ashe KH, Liao D (2010) Tau mislocalization to dendritic spines mediates synaptic dysfunction independently of neurodegeneration. Neuron 68:1067-1081. CrossRef Medline

Hussaini SA, Kempadoo KA, Thuault SJ, Siegelbaum SA, Kandel ER (2011) Increased size and stability of CA1 and CA3 place fields in HCN1 knockout mice. Neuron 72:643-653. CrossRef Medline

Luebke JI, Amatrudo JM (2012) Age-related increase of sIAHP in prefrontal pyramidal cells of monkeys: relationship to cognition. Neurobiol Aging 33:1085-1095. CrossRef Medline

Matthews EA, Linardakis JM, Disterhoft JF (2009) The fast and slow afterhyperpolarizations are differentially modulated in hippocampal neurons by aging and learning. J Neurosci 29:4750-4755. CrossRef Medline

McNaughton BL, Battaglia FP, Jensen O, Moser EI, Moser MB (2006) Path integration and the neural basis of the "cognitive map." Nat Rev Neurosci 7:663-678. CrossRef Medline

Navratilova Z, Giocomo LM, Fellous JM, Hasselmo ME, McNaughton BL (2012) Phase precession and variable spatial scaling in a periodic attractor map model of medial entorhinal grid cells with realistic after-spike dynamics. Hippocampus 22:772-789. CrossRef Medline

Nolan MF, Malleret G, Dudman JT, Buhl DL, Santoro B, Gibbs E, Vronskaya S, Buzsáki G, Siegelbaum SA, Kandel ER, Morozov A (2004) A behavioral role for dendritic integration: HCN1 channels constrain spatial memory and plasticity at inputs to distal dendrites of CA1 pyramidal neurons. Cell 119:719-732. CrossRef Medline

Nolan MF, Dudman JT, Dodson PD, Santoro B (2007) HCN1 channels control resting and active integrative properties of stellate cells from layer II of the entorhinal cortex. J Neurosci 27:12440-12451. CrossRef Medline
Oh MM, Oliveira FA, Disterhoft JF (2010) Learning and aging related changes in intrinsic neuronal excitability. Front Aging Neurosci 2:2. CrossRef Medline

Onslow AC, Bogacz R, Jones MW (2011) Quantifying phase-amplitude coupling in neuronal network oscillations. Prog Biophys Mol Biol 105: 49-57. CrossRef Medline

Ormond J, McNaughton BL (2015) Place field expansion after focal MEC inactivations is consistent with loss of Fourier components and path integrator gain reduction. Proc Natl Acad Sci U S A 112:4116-4121. CrossRef Medline

Palop JJ, Chin J, Roberson ED, Wang J, Thwin MT, Bien-Ly N, Yoo J, Ho KO, Yu GQ, Kreitzer A, Finkbeiner S, Noebels JL, Mucke L (2007) Aberrant excitatory neuronal activity and compensatory remodeling of inhibitory hippocampal circuits in mouse models of Alzheimer's disease. Neuron 55:697-711. CrossRef Medline

Pastoll H, Ramsden HL, Nolan MF (2012) Intrinsic electrophysiological properties of entorhinal cortex stellate cells and their contribution to grid cell firing fields. Front Neural Circuits 6:17. CrossRef Medline

Pastoll H, Solanka L, van Rossum MC, Nolan MF (2013) Feedback inhibition enables $\theta$-nested $\gamma$ oscillations and grid firing fields. Neuron 77: 141-154. CrossRef Medline

Ramsden M, Kotilinek L, Forster C, Paulson J, McGowan E, SantaCruz K, Guimaraes A, Yue M, Lewis J, Carlson G, Hutton M, Ashe KH (2005) Age-dependent neurofibrillary tangle formation, neuron loss, and memory impairment in a mouse model of human tauopathy (P301L). J Neurosci 25:10637-10647. CrossRef Medline

Rocher AB, Crimins JL, Amatrudo JM, Kinson MS, Todd-Brown MA, Lewis J, Luebke JI (2010) Structural and functional changes in tau mutant mice neurons are not linked to the presence of NFTs. Exp Neurol 223: 385-393. CrossRef Medline

Santacruz K, Lewis J, Spires T, Paulson J, Kotilinek L, Ingelsson M, Guimaraes A, DeTure M, Ramsden M, McGowan E, Forster C, Yue M, Orne J, Janus C, Mariash A, Kuskowski M, Hyman B, Hutton M, Ashe KH (2005) Tau suppression in a neurodegenerative mouse model improves memory function. Science 309:476-481. CrossRef Medline

Schindelin J, Arganda-Carreras I, Frise E, Kaynig V, Longair M, Pietzsch T, Preibisch S, Rueden C, Saalfeld S, Schmid B, Tinevez JY, White DJ, Hartenstein V, Eliceiri K, Tomancak P, Cardona A (2012) Fiji: an opensource platform for biological-image analysis. Nat Methods 9:676-682. CrossRef Medline

Spires TL, Orne JD, SantaCruz K, Pitstick R, Carlson GA, Ashe KH, Hyman BT (2006) Region-specific dissociation of neuronal loss and neurofibrillary pathology in a mouse model of tauopathy. Am J Pathol 168: 1598-1607. CrossRef Medline

Stensola H, Stensola T, Solstad T, Frøland K, Moser MB, Moser EI (2012) The entorhinal grid map is discretized. Nature 492:72-78. CrossRef Medline

Van Cauter T, Poucet B, Save E (2008) Unstable CA1 place cell representation in rats with entorhinal cortex lesions. Eur J Neurosci 27:1933-1946. CrossRef Medline

Verret L, Mann EO, Hang GB, Barth AM, Cobos I, Ho K, Devidze N, Masliah E, Kreitzer AC, Mody I, Mucke L, Palop JJ (2012) Inhibitory interneuron deficit links altered network activity and cognitive dysfunction in Alzheimer model. Cell 149:708-721. CrossRef Medline

Witton J, Staniaszek LE, Bartsch U, Randall AD, Jones MW, Brown JT (2014) Disrupted hippocampal sharp-wave ripple-associated spike dynamics in a transgenic mouse model of dementia. J Physiol. Advance online publication. Retrieved November 18, 2015. doi: 10.1113/jphysiol.2014.282889. CrossRef Medline

Yoshida M, Jochems A, Hasselmo ME (2013) Comparison of properties of medial entorhinal cortex layer II neurons in two anatomical dimensions with and without cholinergic activation. PLoS One 8:e73904. CrossRef Medline 